OPEN ACCESS

Edited by:

Irene S. Soares,

University of São Paulo, Brazil

Reviewed by:

Gaurav Gupta,

NIIT University, India

Manuel Ritter,

University Hospital Bonn, Germany

Deborah Negrão-Corrêa,

Federal University of Minas

Gerais, Brazi

*Correspondence:

Momar Ndao

Momar.ndao@mcgill.ca

Specialty section:

This article was submitted to

Parasite Immunology,

a section of the journal

Frontiers in Immunology

Received: 19 May 2021

Accepted: 26 July 2021

Published: 19 August 2021

Citation:

Perera DJ and Ndao M (2021)

Promising Technologies in the

Field of Helminth Vaccines.

Front. Immunol. 12:711650. doi: 10.3389/fimmu.2021.711650

\section{Promising Technologies in the Field of Helminth Vaccines}

\author{
Dilhan J. Perera ${ }^{1,2}$ and Momar Ndao ${ }^{1,2,3,4^{*}}$ \\ ${ }^{1}$ Division of Experimental Medicine, McGill University, Montreal, QC, Canada, ${ }^{2}$ Program of Infectious Diseases and Immunity \\ in Global Health, Research Institute of the McGill University Health Centre, Montreal, QC, Canada, ${ }^{3}$ Department of \\ Microbiology and Immunology, McGill University, Montreal, QC, Canada, ${ }^{4}$ National Reference Centre for Parasitology, \\ Research Institute of McGill University Health Centre, Montreal, QC, Canada
}

Helminths contribute a larger global burden of disease than both malaria and tuberculosis. These eukaryotes have caused human infections since before our earliest recorded history (i.e.: earlier than 1200 B.C. for Schistosoma spp.). Despite the prevalence and importance of these infections, helminths are considered a neglected tropical disease for which there are no vaccines approved for human use. Similar to other parasites, helminths are complex organisms which employ a plethora of features such as: complex life cycles, chronic infections, and antigenic mimicry to name a few, making them difficult to target by conventional vaccine strategies. With novel vaccine strategies such as viral vectors and genetic elements, numerous constructs are being defined for a wide range of helminth parasites; however, it has yet to be discussed which of these approaches may be the most effective. With human trials being conducted, and a pipeline of potential antihelminthic antigens, greater understanding of helminth vaccine-induced immunity is necessary for the development of potent vaccine platforms and their optimal design. This review outlines the conventional and the most promising approaches in clinical and preclinical helminth vaccinology.

\begin{abstract}
Keywords: helminth, vaccine, adjuvant, nucleic acid vaccine, recombinant protein vaccine, viral vector, next generation vaccine, next generation vaccinology
\end{abstract}

\section{INTRODUCTION}

Neglected tropical diseases (NTDs) affect approximately one sixth of the world's population (1). Of these, the group which affects the largest population is the helminths $(2,3)$. Parasitic worms are some of the most ancient pathogens; eggs from Schistosoma for example have been discovered as early as 1200 B.C. in Egyptian mummies (4). Although these worms have been around for millennia, any of them have yet to be eradicated.

Helminths are diverse, comprising over 280 species which can infect humans (5). This number increases dramatically when the one health approach is also considered, including animals. Broadly, these worms are classified into two categories based on morphology: nematodes (roundworms), and platyhelminths (flatworms). The platyhelminths can be further divided into cestodes (tapeworms), and trematodes (flukes). A chart of the most prominent helminths can be found in Figure 1. Despite infections being most common among rural communities in tropical and subtropical regions, some of these worms can be found globally. 
A
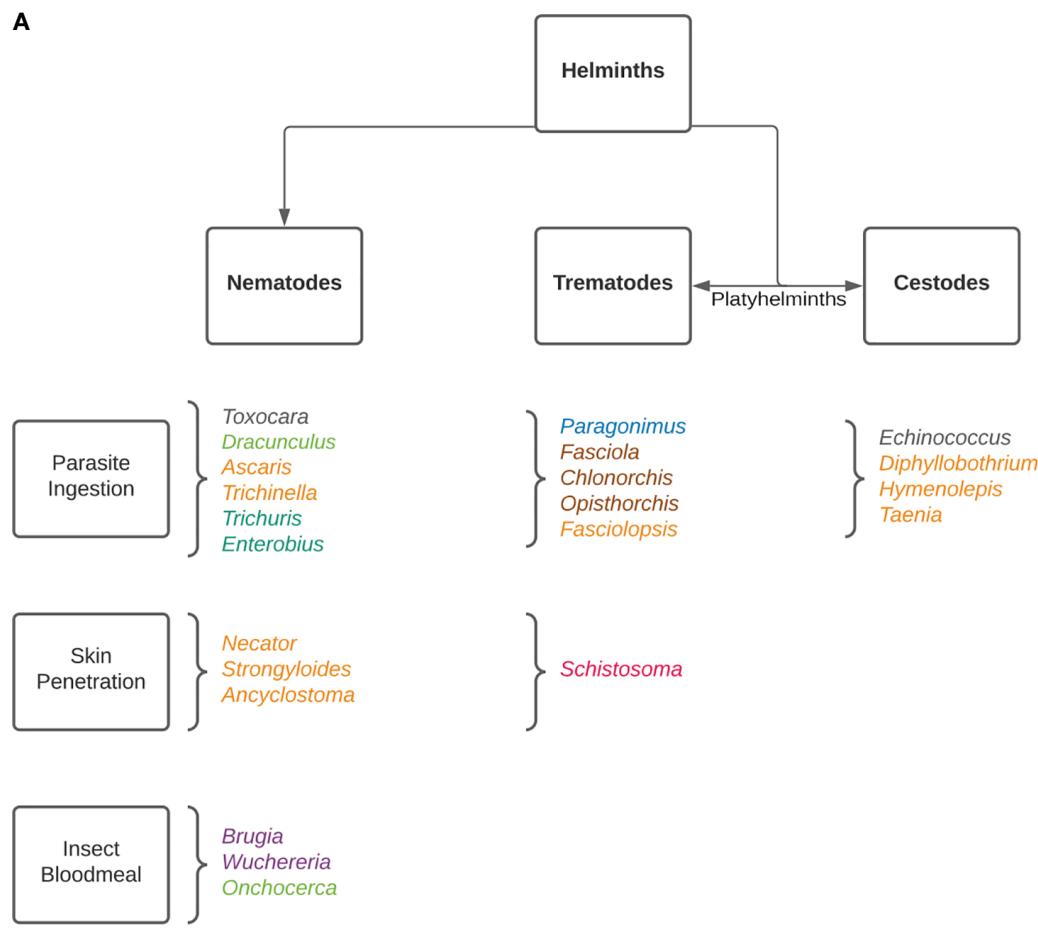

B

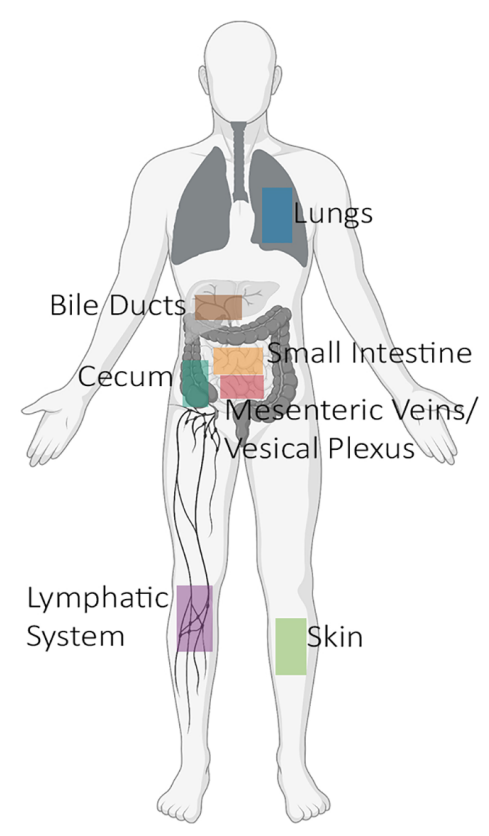

FIGURE 1 | Common human helminths. A non-exhaustive list of human infecting helminths can be found in (A) categorized by their morphologies and means of infection. Helminths are named according to genus. To further demonstrate the complexity of these worms' life cycles their host niches have been shown in (B), where adult worms reside. In the case of Toxocara, the life-cycle stops at a larval stage in humans, and can be found in various organs. Echinococcus oncospheres are released in the intestines, and hydatid cysts can also develop in various organs. Created with BioRender.com.

The prevalence of helminths can be attributed to their extraordinary ability to modulate the immune system. This quality allows them to suppress responses that could result in their elimination, helping them establish chronic infections. Host immunity has developed to limit pathology, resulting in many asymptomatic cases (6) and contributing to the neglect of helminthic infections. This is exceedingly apparent in the case of Mansonella spp. (7). However, these parasites can cause a spectrum of disease including debilitating morbidity, while milder cases compromise immunity to other vaccines $(8,9)$ and incoming infections. In endemic regions, chronic helminth infections lead to increased vulnerability to other pathogens such as $\operatorname{HIV}(10,11)$, malaria $(12,13)$, and even diseases like cancer (14-17). Further, helminth coinfections with other pathogens or other helminths can make prognoses worse. For example, bloodfluke Schistosoma becomes more deadly in Egypt where hepatitis $\mathrm{C}$ virus is prevalent leading to severe liver disease (18). Moreover, the nematode Strongyloides was shown to reduce monocyte and $\mathrm{T}$ cell activation increasing the pathogenicity of tuberculosis infections (19), and human T-cell leukemia virus 1 (20).

Currently, helminth infections are resolved using drug therapy and prevented by various methods including vector control, health education, and programs of water, sanitation, and hygiene (WASH). These efforts have been notable in cases such as soil transmitted helminths (STH) in China (21) and filariasis in Thailand (22) and Sierra Leone (23), among others. Yet in many affected regions despite mass drug administration (MDA) and WASH programs, helminths remain a problem (24, 25) due to low drug efficacies, reinfection, and a lack of other control measures. Additionally, as many helminths are treated with a limited number of drugs, resistance to anthelmintics is emerging for several species $(26,27)$. Unlike in the case of guinea worm (28), where cases have dropped from 3.5 million in 1986 to 27 in 2020 (29) by community-based education, the elimination of many other helminths can't be accomplished using singular control measures alone. To reach WHO goals of helminth elimination, various tools (MDA, vector control, education, etc.) should be combined; vaccines make an important addition to this multipronged strategy.

Vaccination has been essential to the excision of several pathogens (30), yet to date there are no anti-helminth vaccines licensed for human use. Helminths are eukaryotic organisms possessing many characteristics which make their targeting by vaccination methods difficult. Helminths are multicellular invertebrates, which exhibit complex life cycles with different life stages, often occupying vectors for transmission, and infecting multiple hosts both intermediate and definitive. Through the study of paleoparasitology we know that helminths, similar to other parasites, have co-evolved with humans (4) and have undergone unique adaptations that allow 
them to evade the immune system (31), often co-living undetected. These immune evasion techniques are essential to their ability to establish chronic infections.

However, the world of helminth vaccinology is not so dire. Research has shown protection among individuals, although many of these correlates remain unelucidated. In the case of lymphatic filariasis (LF), caused by species Wuchereria bancrofti, Brugia malayi, and B. timori, mathematical modeled studies suggest the emergence of herd immunity in endemic communities (32). More recently, evidence shows that prevalence of infection with LF shares a negative correlation with age. It was found that younger individuals are more susceptible to infection (33), speculating that protective immunity may be developed with time. Similarly, protection from Schistosoma spp. has been witnessed over multiple rounds of praziquantel therapy, although immunity takes years and is rarely sterile (34). The proposed mechanism of protection involves the release of cryptic antigens, which are normally hidden to the host immune system, upon parasite death and degradation. After multiple exposures to these antigens, immunity may be developed which target future schistosome infections (35).

Numerous studies and models have additionally shown the phenomenon of concomitant immunity where adult parasites will prevent reinfection to avoid superinfection, protecting both the host and themselves. Penetration from Echinococcus oncospheres is immunogenic and leads to significant acquired resistance against egg reinfection (36). This immunity is also utilized by Schistosoma spp. $(37,38)$, although the mechanism of protection remains controversial. A recent review by Buck et al., propose the excretory/secretory molecules and vesicles of adult worms may direct an immune response which targets incoming larval parasites (39). Analogous protection has also been demonstrated in calves (40), supporting the findings that Dictyocaulus viviparus larvae are able to induce protective immunity from homologous reinfection (41), limiting host parasite burden. Even female LF worms when subcutaneously implanted are able to partially protect from superinfection in animal models (42-44).

For these reasons, and the discovery and publishing of other correlates of immunity, it is our belief that there is a strong rationale for the development of effective helminth vaccines. Three vaccines for livestock are currently commercially available against D. viviparus (bovine lung worm), Haemonchus contortus (barber's pole worm), and Echinococcus granulosus (45). These multi-dose vaccines are effective and reduce parasite burden up to $98 \%, 94 \%$, and $100 \%$ respectively. Vaccines for human use are currently in development, with promising constructs in clinical and preclinical trials. This review will summarize various helminth vaccination techniques and compare their efficacy for helminth protection with an emphasis on novel technologies.

\section{IMMUNE RESPONSE TO HELMINTHS}

The dominant immune response to helminths is widely accepted to be type 2 (Th2) (46), through interactions between the innate immune system, antigen presenting cell (APC) and T helper cell complexes, and the combination of IL4 and IL33. This feature is reflected in many helminth species regardless of their biological niche in the body (i.e., vasculature, intestinal lumen, subcutaneous sites, lymphatic system, etc.), and in most cases coordinated Th2 responses have been demonstrated to protect from parasitic worms (46). Increased levels of classical Th2 cytokines: IL4, IL5, and IL13 have been associated with lower parasite burdens $(47,48)$ by activating eosinophils, mast cells, alternatively activated macrophages, and antibody defenses like IgE (49-51). Additional cytokines IL6 and IL9 have also been implicated in immunity to filariasis and human whipworm Trichuris trichiura (52-54).

Most helminths also invoke immunoregulatory responses by upregulating TGF $\beta$ production or releasing parasite-derived TGF $\beta$ mimics, to expand regulatory $\mathrm{T}$ cell differentiation and promote their persistence. Macrophages and leukocytes have been implicated in IL10 and TGF $\beta$ production, downregulating parasite clearing $\mathrm{T}$ cell responses and cytokine production (55-57). These regulatory elements enhance parasite survival by leading to the increase of regulatory dendritic cells, regulatory $\mathrm{B}$ cells, and alternatively activated macrophages - permitting the development of chronic infections. At first glance the reduction of immune activation may seem to be solely at the cost of the host, yet this IL10 pathway also moderates destructive immune responses, protecting the host from self-damage $(58,59)$.

The upregulation of Th2 and regulatory $\mathrm{T}$ cell (Treg) responses in helminth infections leads to a "modified Th2" response (60), simplified in Figure 2. This suppresses Th1 immunity and is further complicated by Th17 function. Helminths which lead to liver disease tend to increase Th17 cytokines and worsen inflammatory pathologies (61). Dendritic cell derived IL6, TGF $\beta$, and IL23 cause naïve CD4+ T cell differentiation into Th17 cells (62). This differentiation however is dampened by both helminth induced Th2 and Treg responses.

Although it is acknowledged that Th2 responses are important effectors of helminth protection, it is unclear which specific immune mechanisms must be rescued by vaccination. As such, through various vaccination strategies, the search for the ideal anti-helminth immune response continues.

\section{IRRADIATED HELMINTH VACCINES}

Similar to attenuated viral vaccines, among the first proposed vaccines for helminths were radiation attenuated. First tested in the 1950 s, and leading to the commercial vaccine Dictol ${ }^{\circledR}$, was the live attenuated vaccine against $D$. viviparus in cattle. This vaccine is an oral vaccination with irradiated larvae that are unable to mature into adult worms but survive long enough to stimulate protective immune responses. Sprouting from this research came various vaccine constructs developed using X-ray, $\gamma$-ray, UV, and even microwave irradiation against a diverse collection of helminths including but not limited to: LF (63-66), amphistomes (67), STH (68-73), Fasciola spp. (74-77), Toxocara canis $(78,79)$, Trichinella 


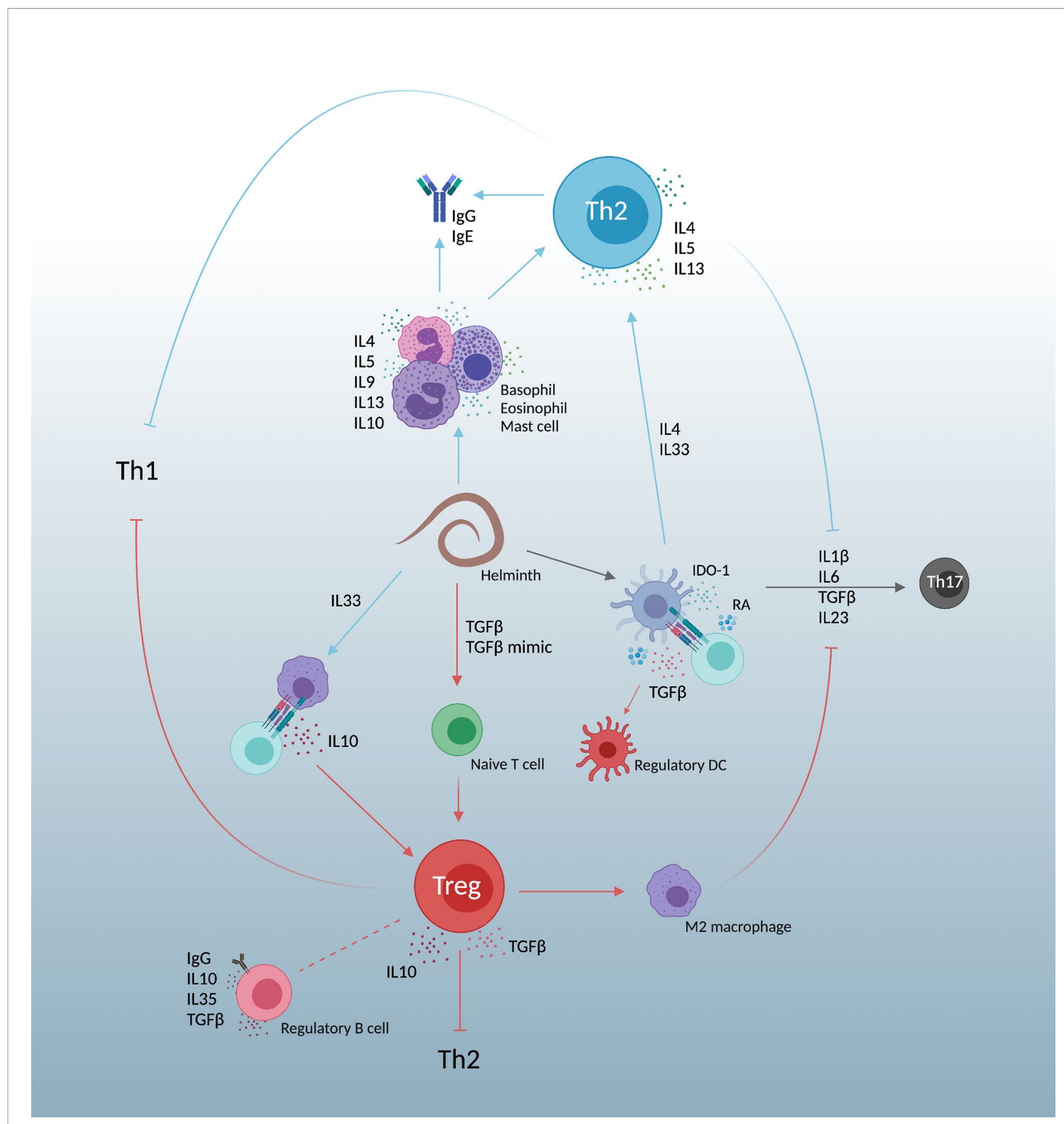

FIGURE 2 | A simplified view of the "modified Th2" response created by helminth infections. Responses are heavily Th2, promoting IL4, IL5, and IL13. Simultaneous expansion of regulatory T cell immunity by host TGF $\beta$ and parasite TGF $\beta$ mimics dampen Th2 skewing, allowing parasite persistence and decreasing both Th1 and Th17 responses. Created with BioRender.com.

spp. (80, 81), Onchocerca volvulus (82-84), Clonorchis sinensis (85), and Echinococcus granulosus (86).

Perhaps the most widely researched irradiated helminth vaccines are against Schistosoma spp. Onwards of 1962, researchers have tested irradiated schistosome vaccines (RA vaccines) in animal models of the most clinically relevant species: S. mansoni (87-89),
S. japonicum $(90,91)$, and S. haematobium (92-95). This vaccination strategy has been referred to as the "gold standard" for years, as it consistently generates high levels of protection against challenge.

Most groups show that protection increases with additional boosting doses of irradiated parasite $(70,81)$, although the amount of radiation is controversial and may be species specific. 
In 1986, a study showed that increased levels of $\gamma$ radiation afforded increased protection from Fasciola gigantica (77). In this study, metacercariae were irradiated with 3 and $20-\mathrm{krad}$ and were used to immunize zebu calves. These vaccinated groups gave protection from adult parasites of $77 \%$ and $88 \%$ respectively, with immunizing radiated parasites only developing into adult worms in the 3-krad group. In contrast, Harrison et al. showed that against $S$. haematobium, cercariae that were given two to three doses of 20krad radiation were more effective than doses of 3-krad, 60-krad, and much more effective than a single vaccination (95).

The correlates of immunity provided by these vaccines are debated within the literature. In the case of RA vaccines, an importance has been placed on the expression of IFN $\gamma$ and Th1 immune responses (96-99), despite the protection delivered by Th2 responses for most helminths $(65,72,83,100)$.

Although effective, these vaccines pose challenges as human vaccines for several reasons. They are composed of live parasites which require vectors and experimental models to be grown and maintained. This makes culturing large amounts of helminths impractical. Moreover, the heterogenous nature of eukaryotic worms makes batch manufacturing of a homogenous vaccine impossible. Additionally, in many cases of these constructs, some viable parasites will mature into adult worms and cause patent infections in immunized individuals. Due to logistical and ethical reasons it is unlikely that an irradiated helminth vaccine will be developed for human use. However, the protection mediated by these vaccines further rationalizes the ability to induce protective immunity from parasitic worms, and this research has been used to give insight on the development of promising subunit vaccines.

\section{SUBUNIT VACCINES AND ANTIGEN SELECTION}

To ameliorate some of the challenges of developing radiation attenuated helminth vaccines, many recent strategies utilize subunit vaccines. In this case the most promising components, or antigens, which best stimulate the immune system are administered. By carefully selecting appropriate antigens, vaccine development can be targeted to enhance protection and minimize possible side effects (101). Antigens are habitually identified by proteomic analysis on crude homogenates of helminths and then chosen based on immunogenicity and their ability to stimulate an immune response. In recent years, new technologies have allowed the identification and prediction of antigens using immunoinformatics $(102,103)$ and in silico approaches which use computer software to anticipate $\mathrm{T}$ cell epitopes given pathogen genome analysis (104). These antigens can then be isolated from parasites, produced as recombinant proteins, or delivered using innovative vaccine strategies.

\section{COMBINING RECOMBINANT PROTEINS WITH NOVEL ADJUVANTS}

To better enhance immune responses, several vaccine efforts have employed the use of novel adjuvants - some of which have not yet been approved for human use. Antigens used as vaccine targets often lack immunogenicity. Helminth antigens, capable of stimulating immune responses, have been known to possess inbuilt adjuvanticity $(105,106)$. Nevertheless, adjuvants can be used to augment or skew immunogenicity to enhance protective effects. The most common adjuvants used in US vaccines include: formulations of aluminum, AS04, MF59, AS0 $1_{B}$, and CpG dinucleotides (107). These adjuvants are effective and have demonstrated protective capacities, explaining their use in clinical applications; however, the field of adjuvant discovery is expanding, and several innovative adjuvants are in preclinical trials with promising results.

Many helminth vaccines in clinical development utilize the synthetic TLR4 agonist, glucopyranosyl lipid adjuvant (GLA). Naturally, some preclinical efforts have followed the same path. A recent effort to protect from $S$. mansoni involved adjuvanting the parasitic large subunit of calpain (Sm-p80) with a stable emulsion of GLA (GLA-SE). This vaccine, tested in baboons, demonstrated a female worm specific reduction of $93.45 \%$, with an overall protection of $65.9 \%$ (108). Although adult worm reduction is enticing, perhaps a more important metric is the reduction of tissue eggs. Schistosoma spp. pathology is induced mainly through egg deposition and Th2 responses against egg antigens, which in support of this vaccine, is reduced by $89.95 \%$. All of these greatly surpass the $40 \%$ vaccine standard set forth by the $\mathrm{WHO}$ and almost reach a $70 \%$ vaccine standard which may be more appropriate in light of recent vaccine efforts (109). GLASE has also provided protection from LF in a $B$. malayi mouse model. In this case, a tetravalent vaccine was prepared using the following recombinant antigens: heat shock protein 12.6, abundant larval transcript-2, tetraspanin large extracellular loop, and thioredoxin peroxidase (rBm-HAXT). After the threedose immunization schedule administered subcutaneously, vaccinated animals displayed high titers of antigen specific IgG in serum and peritoneal fluid, predominating in IgG1 with expansions of IgG2. A significant protection of $88.05 \%$ was obtained compared to $79.47 \%$ and $78.67 \%$ given when rBmHAXT was adjuvanted with conventional alum and mannosylated chitosan (MCA) respectively. All vaccines tested increased the percentage of central memory $\mathrm{T}$ cells $\left(\mathrm{T}_{\mathrm{CM}}\right)$ in the spleen, with an increased expression of IFN $\gamma$ specifically in those cells from the GLA-SE vaccine arm (110). When this vaccine was tested in a non-human primate (NHP) model, despite adding another boosting immunization, vaccine efficacy dropped drastically to $57.14 \%$ protection (111). Interestingly, in this different animal model, the immune landscape conferred by this vaccine seems to be more balanced Th1/Th2 versus the mouse model where the Th1 bias was apparent in splenocyte expressed cytokines IFN $\gamma$ and IL2, among others. In the NHP study, $\mathrm{T}_{\mathrm{CM}}$ cells were found to be expressing more IL4, while effector memory $\mathrm{T}$ cells $\left(\mathrm{T}_{\mathrm{EM}}\right)$ were found to be contributing the IFN $\gamma$. This balanced response was seen in peripheral blood mononuclear cell (PMBC) cytokine expression of IFN $\gamma$, IL12p70, IL4, IL5, and TNFa, among others. Despite the drop in parasite burden reduction, antibodies developed in the NHP study were able to mediate protection via antibody dependent 
cellular mediated cytotoxicity (ADCC) by recognizing, covering, and killing L3 larvae in vitro.

ADCC has been a proposed mechanism of protection in other helminth vaccines including our work on $S$. mansoni using an adjuvanted Cathepsin B (SmCB). The larval stage of S. mansoni passes through the lungs and is vulnerable to antibody and cell mediated effectors. When we combined SmCB with Montanide ISA $720 \mathrm{VG}$ (ISA 720), lung stage protection was reported to be provided by ADCC, specifically through macrophages, natural killer (NK) cells, and CD4+ and CD8+ T cells (112). By conducting in vitro larval killing assays with and without cells and sera from immunized mice, it was shown that CD4+ T cells and NK cells were able to significantly increase killing only in the presence of immune sera. The necessity of cells and sera from immunized animals for larval killing makes an argument that protection is mediated by ADCC. In the context of a SmCB and ISA 720 immunized lung, CD4+ T cells and NK cells are key players in parasitic killing, aided by $\mathrm{CD} 8+\mathrm{T}$ cell and macrophage killing, dependent on antibodies. The resulting protection from this vaccine was approximately $60 \%$ with a mixed Th $1 /$ Th 2 based immune response (113). Seppic-produced Montanide series adjuvants are produced with GMP as well as Montanide ISA 51 VG have been developed as human therapeutics. Among these are many other Montanide adjuvants which are used in veterinary vaccines. ISA 720 has also been used in a vaccine against Ascaris suum although protection was higher when the target antigen, As16, was formulated in alum (114). Despite the protection afforded by the Th1/Th2 skewing S. mansoni vaccine, in the case of $A$. suum protection was increased with Th2 responses. Other Montanide based vaccines have been developed against Fasciola spp. (115-118), Schistosoma japonicum (119), Trichinella spiralis (120, 121), and LF (122) to name a few.

Other vaccines against Fasciola spp. have been developed using the adjuvant Quil A. This saponin based adjuvant contains the water-extractable fraction of the South American tree Quillaja saponaria Molina and has been used in several veterinary applications $(123,124)$. With antigens Fasciola hepatica Cathepsin L1 (FhCL1) (125), S. mansoni $14 \mathrm{kDa}$ (Sm14) (126), and F. hepatica peroxiredoxin (FhPRX) (127), and the former three in combination (128), Quil A adjuvanting was unable to significantly reduce parasite burden, although vaccination was able to deliver reductions in pathological events. When a group employed the use of FhCL1 mimotopes (peptides which mimic antigenic epitopes), Quil A was able to reduce parasite burden by $67.17 \%$ in sheep (129) and $79.53 \%$ in goats (130), suggesting that in some cases choosing appropriate portions of an antigen might be preferable to using whole antigens.

Quil A is an InvivoGen product and has not been developed for human use. This is also the case for AddaVax, a squalenebased oil-in-water nano-emulsion. However, AddaVax is a formulation similar to MF59 which is licensed for human use in 30 countries (131), making it an excellent mimetic for preclinical research. Although in animal models of A. suum, when As16 was adjuvanted with AddaVax, there was no protection observed (114), when combined with As37, AddaVax reduced lung larval burden by $48.7 \%$ (132). In this context, AddaVax increased both IgG subtypes IgG1 and IgG2c and cytokines IL4, IL5, IL10, IL13, and TNF $\alpha$. This data corroborates our work combining AddaVax with SmCB in a prophylactic vaccine for $S$. mansoni. We saw robust antigen specific humoral responses of both IgG1 and IgG2c. In addition, we observed a significant increase in systemic CD4+ and CD8+ T cells expressing IFN $\gamma$ along with a splenic immune landscape which skewed more Th2 and anti-inflammatory than when SmCB was combined with ISA 720 and sulfated lactosyl archaeol archaeosomes. Overall, this mixed Th1, Th2, and anti-inflammatory response led to both significantly reduced visual pathology in vaccinated mouse livers and egg granuloma sizes. Moreover, this vaccine reduced parasite burden by $86.8 \%$, $78 \%$, and $83.4 \%$ in adult worms, hepatic eggs, and intestinal eggs respectively (133). The only helminth vaccine tested within the last 5 years using MF59 is one developed for Onchocerca volvulus which conferred $87 \%$ protection in mice when adjuvanting the O. volvulus antigen OvRAL2 (134). Although MF59 is largely used in influenza vaccines, the protective responses of AddaVax seen in parasitic models may warrant its application to helminth vaccinology.

S. mansoni vaccines have been in development for over 30 years and recent work has been conducted using the adjuvant adaptation (ADAD) system originally developed in 2004 for Fasciola hepatica (135). This vaccination system involves two subcutaneous injections. The first "adaptation" immunization contains a combination of synthetic aliphatic diamine and saponins emulsified in a non-mineral oil. Five days later, a second immunization is given with the same elements including antigen. A three-dose vaccine developed using predicted $\mathrm{B}$ and $\mathrm{T}$ cell epitopes of an S. mansoni kunitz-type serine protease inhibitor was tested using the ADAD system. Both epitopes used conferred protection, however the $\mathrm{T}$ cell epitope delivered a slightly higher parasite burden reduction of $91 \%$ in female adult worms than the B cell epitope vaccine ( $89 \%$ reduction). Interestingly, both these vaccines were sex specific and male adult worms were unaffected. Contrary to the worm reduction, the $\mathrm{B}$ cell epitope delivered a higher reduction in gut liver eggs (77-81\%) compared to the T cell epitope vaccine $(57-77 \%)$. Still, both had a reduced number of egginduced granulomas (136). A second effort was also tested against $S$. mansoni using the ADAD vaccination system. Two vaccines were developed comparing recombinant protein expression systems, both of them two-dose, targeting F. hepatica fatty acid binding protein [Fh15 (E. coli expressed) and Fh15b (baculovirus expressed)] which show a $44 \%$ identity to Sm14 in clinical trials as a $S$. mansoni vaccine target. This study demonstrated that when expressed in E. coli, Fh15 delivered higher protection from schistosomiasis than when expressed by baculovirus. This finding supports the hypothesis that post-translational modifications by different expression systems can impact the immune response elicited by recombinant antigens, as this group found that delivering a baculovirus expressed Fh15 resulted in an impairment of the humoral response (137). The E. coli expressed Fh15 vaccine reduced parasite burden by $64 \%$, 
$69 \%, 58 \%, 67 \%, 61 \%$, and $77 \%$ in adult worms, female worms, male worms, hepatic lesions, and eggs per gram of liver and intestines respectively. Despite this protection being lower than the protease inhibitor $\mathrm{ADAD}$ vaccine, the reality of a schistosome vaccine targeting a Fasciola antigen could mean cross protection from both helminths, which is incredibly alluring for coendemic regions.

Although the ADAD system seems to be effective, the advancement of this vaccine strategy may prove to be infeasible as each immunization consists of two injections five days apart. The first vaccine described would result in six necessary injections, and the second would be four. In endemic regions, vaccine compliance and the lack of infrastructure will challenge the ability to properly vaccinate the population. Current helminth vaccines use three immunizations as a standard, however effective vaccine strategies requiring fewer boosting immunizations should be explored.

\section{NUCLEIC ACID VACCINES}

In recent years, the push for nucleic acid vaccines have become more prominent. To our knowledge there have been no RNA vaccines developed against helminthic infections, however DNA vaccines have been tested since the early 2000s. Genetic vaccines deliver antigen RNA or DNA which are then translated within the host for in vivo antigen expression. Internal delivery of antigens using DNA is compelling as it is easy to manufacture and has been demonstrated to induce both humoral and cellmediated immune responses in animals $(138,139)$. DNA is also stable at ambient temperatures (140) which is highly practical for use in endemic and rural regions.

A common obstacle of DNA vaccines seems to be a lack of immunogenicity when used in humans, which groups have been attempting to ameliorate through the use of molecular adjuvants and advanced DNA vector design $(141,142)$. DNA vaccines may also pose safety risks associated with biodistribution and persistence, as well as the potential for plasmid-based vaccines to be integrated into the microbiome genome. To subside some of these fears, Liu et al. show that although their S. japonicum plasmid-based DNA vaccine can be found in every tissue site tested, it was successfully cleared by day 120 (143). Additionally, after vaccination with their plasmid containing a hygromycin resistance gene, intestinal microfloras were unable to grow on hygromycin containing plates, demonstrating that the microbiome of vaccinated animals was not found to uptake the plasmid. To confirm, they also ran a PCR for the hygromycin gene and their gene of interest on DNA extracted from intestinal and excremental samples and obtained negative results. To date there are no DNA vaccines approved for human use, although four are licensed for veterinary use (144) and there are over 600 clinical trials that focus on DNA vaccination registered in the USA.

In a preclinical context, DNA vaccines have been developed against several helminths including Fasciola hepatica (145), hookworm (146), and Schistosoma spp. (147-150) for example.
However, many of these vaccines deliver lackluster parasite burden reductions, barely reaching 50\%.

Several efforts have been made to produce a DNA vaccine against Trichinella spiralis. In 2013, Tang et al. published their data of a vaccine which reduced parasite burden by $37.95 \%$ (151). This vaccine encoded two antigens [T. spiralis macrophage migration inhibitory factor (TsMIF) and cystatin-like domain protein (Ts-MCD-1)] and was delivered in two doses. They found their vaccine to stimulate Th1 responses, increasing IFN $\gamma$ with no significant changes to IL4 and IL5 expression, similar to the results of a $S$. mansoni DNA vaccine which only reduced parasite burden by $30 \%$ (147). In the same year, a DNA vaccine delivered in 3 doses alongside recombinant protein (Ts87) was able to further reduce parasite burden by $43.8 \%$ (152). This vaccine increased both Th1 and Th2 immune responses with cytokine expression increases of IL2, IL4, IL6, and IFN $\gamma$. It is interesting to note that optimal antigen selection is crucial for protective immunity from helminths. Although the TsMIF+TsMCD-1 vaccine was only partially protective, a DNA vaccine expressing T. spiralis $43 \mathrm{kDa}$ and $45 \mathrm{kDa}$ glycoproteins was able to confer protection of $75.9 \%$ (153). This vaccine also deployed a mixed Th1/Th2 immune response alike the Ts87 vaccine, without the need for additional recombinant proteins. The Ts43+Ts45 vaccine showed increases of IFN $\gamma$, IL4, and IL10, but more striking was the increase in the percent of B220+ B cells when compared to both single antigen DNA vaccines and the PBS control. These data support the idea that both Th1 and Th2 arms of immunity can work synergistically to protect from parasitic worms.

The most significant parasite burden reductions afforded by DNA vaccines can be seen in their use against B. malayi and LF. Gupta et al. has demonstrated the protective efficacy of two DNA vaccines, both of which use a heterologous DNA prime and recombinant protein boost strategy targeting a myosin gene. An initial endeavor gave two immunizations of DNA followed by two protein boosts adjuvanted by Freund's incomplete adjuvant (FIA). This vaccine reduced parasite burden by $75.3 \%$ and showed a $78.5 \%$ reduction in microfilarial density in the blood (154). Antibody responses were shown to kill L3 larvae, and cytokines IL2, IFN $\gamma$, TNF $\alpha$, IL12, IL4 and IL10 were increased after immunization and maintained through challenge. This immunogenicity was increased when their DNA vaccine was delivered along with $\mathrm{CPG}$ dinucleotides and in replacement of FIA. This 4-dose vaccine was now found to reduce parasite burden by $84.5 \%$ with similar cytokine expression and the additional proliferation of CD4+ T cells, CD8 $+\mathrm{T}$ cells, and CD19+ cells. Likely, the increase of dendritic cell (DC) activating markers and $\mathrm{T}$ cell associated markers (CD40, CD80, CD86) observed on DCs from vaccinated animals combatted the APC dysfunction and lack of $\mathrm{T}$ cell responsiveness common to filarial infection $(155,156)$.

DNA vaccines typically promote Th1 immune responses. Although these show promise in models of LF, other helminths may be better targeted by alternative methods of vaccination. This can be seen more explicitly in the Sm-p80 vaccine which has been tested in baboons against $S$. mansoni 
delivered both by DNA vaccines and as adjuvanted protein. The Sm-p80 vaccine has been in development for over a decade, optimizing through various vaccine platforms and adjuvant combinations (157). The most significant protection data from the Sm-p80 DNA vaccines were obtained when a DNA vaccine was boosted by recombinant protein adjuvanted with $\mathrm{CpG}$ dinucleotides, which reduced parasite burden by $47.34 \%$ (157). This reduction is less enticing than that of their adjuvanted recombinant protein vaccine using GLA-SE (65.9\%) (108). Zhang et al. conducted RNA-sequencing on PBMCs, spleen cells, and lymph node cells from baboons vaccinated with their various $\mathrm{Sm}-\mathrm{p} 80$ vaccines to determine functional immune profiles from each. The DNA vaccine presented a relative Th1mediated immune response with $8.41 \%$ of its differentially expressed genes in PBMCs relating to the TLR9 signaling pathway. This was reflected by a predicted deactivation of Th2 pathways in spleen cells and iCOS-iCOSL signaling in both spleen cells and PBMCs. This downregulation of Th2 immunity may have diminished protective correlates, as in previous reports, Sm-p80-mediated protection seems to be enhanced by antibody responses $(108,158)$.

Supported by a hypothesis by Versteeg et al. (159), an interesting avenue of research will be the development of RNA vaccines for helminths which, given the efficacy of their COVID19 counterparts, can be expected in the near future. Their versatility and simple means of production made mRNA vaccines a top contender for prophylactic SARS-CoV-2 vaccines and were exploited by the two earliest vaccines made available by the FDA for COVID-19 emergency use $(160,161)$. RNA vaccines are shown to stimulate potent and safe immune responses in animals (162) and humans (163-165). Although their stability requires a cold-chain, mRNA vaccines have a lowcost manufacturing process, and unlike DNA vaccines, they remain outside the host cell nucleus making them an attractive vaccine vector worth exploring.

\section{VIRAL VECTORED VACCINES}

Since the discovery of vaccines and the efficacy of live attenuated virus vaccines to protect from their wildtype counterparts, the concept of using viruses to fight other infectious agents has evolved over time. Around the introduction of nucleic acid vaccines like DNA and RNA vaccines, delivering genetically modified viruses arrived as another vaccine platform. Viral vectored vaccines utilize the natural infectivity of viruses and their "life" cycle, using host machinery to translate their own genetic elements and incorporated antigens. By using infectious agents to deliver vaccine targets potent cellular responses can be elicited, specifically CD8+ cytotoxic T cells. As in the case of nucleic acid vaccines, since vaccine encoded genes are expressed intracellularly, antigens can be processed and presented on class I major histocompatibility complexes (MHC-I) of APCs. These approaches may be favoured for diseases where cell-mediated immunity can significantly enhance protective responses afforded by humoral immunity or in those cases where antibody production alone is insufficient.

Viral vectored vaccines have been developed against Lassa fever (166), HIV (167), malaria (168), taeniasis (169), and countless others. As each viral vectored vaccine can utilize a different virus, each of their mechanisms of antigen presentation and immune stimulation will vary according to the nature of the virus used. Commonly used viral vectors are adenoviruses, pox viruses, and vaccinia viruses because they are well characterized, each with their own unique features. Although many others have been exploited as vectors, only a few will be touched upon here.

One of the largest limitations to viral vectoring is neutralizing antibodies to the vector from previous viral infections. Vaccine priming doses can also produce neutralizing antibodies which may render boosting immunizations useless. To circumvent this problem, despite groups showing robust $\mathrm{T}$ cell responses regardless of the presence of neutralizing immunity (170), heterologous prime-boost strategies, varying vaccine immunization routes, and the use of viruses which do not circulate in target populations, have been employed.

Several groups have utilized the antigen EG95, a protective vaccine target for Echinococcus granulosus, demonstrating its expression using goatpox virus (171), morbillivirus (172), and on the surface of orf virus $(173,174)$. Protective benefits of only one E. granulosus viral vectored vaccine have been published to date, and this was in a vaccinia virus vector (175). In this model, mice were immunized with $10^{8}$ plaque forming units (PFU) of recombinant vaccinia virus intranasally. Some groups of mice were given a boosting immunization of either recombinant virus or recombinant EG95 prepared with alum and delivered intraperitoneally. The reverse was also tested, where adjuvanted antigen was the priming immunization for a recombinant virus boost. Analysis of EG95-antibody responses showed the highest titers of immunoglobulin in mice which received virus prior to adjuvanted protein, followed by the group administered the reverse. Protective capacity was demonstrated in vitro using an oncosphere killing assay. In this experiment, mouse anti-sera were applied to oncospheres and the highest dilution in which killing was observed was reported. The group in which the highest dilution of sera provided killing was the group first immunized by virus followed by adjuvanted protein. The trend follows that the amount of antigen specific immunoglobulin may be correlated with protection, as those groups with higher titers observed killing at higher dilutions.

The earliest viral vector for Schistosoma spp. developed for $S$. mansoni showed no antigen specific antibody response or protective efficacy (176); however, several have since been deployed as a vector for S. japonicum. In 2010, data were published on a pseudorabies virus (PRV) expressing both S. japonicum fatty acid binding protein and $26 \mathrm{kDa}$ glutathione-S-transferase (177). This vaccine was administered in two doses and increased IL-2 expression from stimulated splenocytes when compared to the negative control. The virus expressing both antigens even significantly increased IFN $\gamma$ production higher than either viral vaccine expressing single antigens. The protection they observed in mice (39.3\% reduction 
of worms) was less than that of sheep (48.5\% reduction of worms), inferring the importance of the animal model used.

Attenuated pseudorabies viruses have been developed against a large number of infectious diseases and have been comprehensively reviewed (178). Although in some cases PRV vectored vaccines have been effective, groups have shown faster antibody responses and recruitment of cell-mediated immunity using adenoviral vectors (179). This schistosomiasis protection delivered by PRV was inferior to another group which expressed S. japonicum triosephosphate isomerase using a human adenovirus serotype 5 vector.

An initial study in mice looked at the immune responses and protective efficacy elicited by various administration routes of a recombinant adenoviral vector including: intramuscular (IM), subcutaneous (SC), and oral administration. Vaccines were administered in three doses, each giving $10^{8} \mathrm{PFU}$ of virus. Oral immunization did not result in a humoral response or significant protection. Although robust antibody titers to antigen were observed in the IM and SC routes of administration at the study endpoint, the question of neutralizing antibodies was not addressed, and humoral responses were not measured throughout immunization. Interestingly, the route of administration caused a shift in the isotype of IgG expressed. SC immunization led to an expansion of IgG1/IgG2c, whereas IM immunization favoured IgG2c. This immune skew was reflected in ELISPOT data from stimulated splenocytes. Splenocytes from mice in the subcutaneously vaccinated group had a higher proportion of IL4 secreting cells to IFN $\gamma$, and in the intramuscular group the opposite was observed. Although both routes delivered protection from infection, the intramuscular or Th1 skewed response may be more desirable giving $54.92 \%$ reduction compared to the SC $37.50 \%$ (180). Protection was further increased when their recombinant adenovirus was delivered in a heterologous prime boost strategy using recombinant protein adjuvanted with FIA. This vaccination method promoted expansion of both antigen specific IgG1 and IgG2c isotypes and reduced parasite burden by $72.09 \%$ in adult worms compared to the recombinant adenovirus alone and adjuvanted protein arms, which reduced adult worms by $50.59 \%$ and $26.67 \%$ respectively (181).

This wave of viral vectoring in vaccinology has been used in many preclinical applications and has expanded into human use in the past years (182-184). Other viral vectors of interest which may be considered include cytomegalovirus, vesicular stomatitis virus, and measles virus due to their large carrying capacities (185), and Newcastle disease virus due to the lack of preexisting virus immunity in human populations (186). Although their use in helminthology is lean, viral vectored vaccines allow for enhanced immunogenicity when compared with other genetic vaccine vectors and should be further investigated.

\section{HELMINTH VACCINES IN CLINICAL TRIALS}

To date the only helminth vaccines in clinical trials have been developed using recombinant protein technology, generally with adjuvants to enhance immunogenicity as summarized in Table 1. These vaccines showed promising data in preclinical studies and have been largely safe and immunogenic in humans. The one exception being the Na-ASP-2 vaccine for human hookworm. Due to the generalized urticaria witnessed with this vaccine (195), hookworm vaccine efforts have shifted to other antigens such as Na-GST-1 and Na-APR-1.

Currently, the only completed phase 3 trial with reported efficacy data is the vaccine for urinary schistosomiasis. Unfortunately, this 4dose vaccine regimen proved to be ineffective in providing sufficient protection from S. haematobium when looking at the delay in reinfection between experimental groups (199). The authors hypothesize that an expansion of antigen specific IgG4 hinders protective responses of IgG3, despite the previously shown protective effects of IgG4 in S. haematobium reinfection (212). Perhaps more likely is their explanation that their efficacy readout was suboptimal, as they were unable to visualize differences in infection intensity in the vaccine group versus the control. Despite this lack of efficacy, the confirmed safety of the Sh28GST vaccine in

TABLE 1 | Helminth vaccines in human clinical trials.

\begin{tabular}{|c|c|c|c|c|c|}
\hline Target Antigen & Adjuvant & Doses & Pathogen & Phase & Ref \\
\hline Glutathione-s-transferase (Na-GST-1) & $\begin{array}{l}\text { Alhydrogel } \\
\text { Alhydrogel + CpG } \\
\text { Alhydrogel + GLA-AF }\end{array}$ & 3 & Hookworm & 1; complete & $(187-190)$ \\
\hline Aspartic protease (Na-APR-1) & $\begin{array}{l}\text { Alhydrogel } \\
\text { Alhydrogel + GLA-AF }\end{array}$ & 3 & Hookworm & 1; complete & $(191)$ \\
\hline $\begin{array}{l}\text { Na-GST-1 + Na-APR-1 } \\
\text { L3 larvae }\end{array}$ & Alhydrogel + GLA-AF & $\begin{array}{l}3 \\
3\end{array}$ & $\begin{array}{l}\text { Hookworm } \\
\text { Hookworm }\end{array}$ & $\begin{array}{l}\text { 1; complete } \\
\text { N/A; complete }\end{array}$ & $\begin{array}{c}(192,193) \\
(194)\end{array}$ \\
\hline Ancyclostoma-secreted protein (Na-ASP-2) & Alhydrogel & 3 & Hookworm & 1; complete and halted & $(195-198)$ \\
\hline Glutathione-s-transferase (Sh28GST) & $\begin{array}{l}\text { Alhydrogel } \\
\text { Alum }\end{array}$ & $\begin{array}{c}4 \\
2,3\end{array}$ & Schistosoma haematobium & $\begin{array}{l}\text { 3; complete } \\
\text { 1; complete }\end{array}$ & $\begin{array}{l}(199,200) \\
(201,202)\end{array}$ \\
\hline Sm14 & GLA-SE & 3 & Schistosoma mansoni & $\begin{array}{l}\text { 2/3; ongoing } \\
2 \text {; complete } \\
1 \text {; complete }\end{array}$ & $\begin{array}{c}(203) \\
(204,205) \\
(206,207)\end{array}$ \\
\hline Tetraspanin (Sm-TSP-2) & $\begin{array}{l}\text { Alhydrogel } \\
\text { Alhydrogel + AP 10-701 } \\
\text { Alhydrogel + GLAAF }\end{array}$ & 3 & Schistosoma mansoni & $\begin{array}{l}\text { 1/2; recruiting } \\
1 ; \text { complete } \\
1 ; \text { complete }\end{array}$ & $\begin{array}{c}(208) \\
(209) \\
(210,211)\end{array}$ \\
\hline
\end{tabular}


humans and the availability of other promising vaccine constructs in preclinical testing suggest the probability of a protective helminth vaccine in the foreseeable future.

Although not a vaccine for helminths, the furthest progressed human parasite vaccine is the Mosquirix ${ }^{\mathrm{TM}}$ (RTS,S/AS01) vaccine which was given a favorable opinion by the European Medicines Agency (EMA) and has been authorized by the National Regulatory Authorities of Ghana, Kenya, and Malawi for use in pilot areas. It combines the central repeat region of the circumsporozoite protein of Plasmodium falciparum onto a hepatitis B surface antigen as a carrier, with the adjuvant AS01 and was recently reviewed (213). Within the countries included in the phase 3 trial, RTS,S/AS01 prevented 39\% of malaria cases and $29 \%$ of severe malaria over four years (214). Although protection can't be compared to helminths, since malaria is an intracellular protozoan parasite, the success of RTS,S/AS01 gives hope to other parasitic vaccine efforts.

\section{HELMINTH VACCINE INDUCED PROTECTION}

The central dogma around helminth protection has encompassed Th2 immunity for decades. This includes cytokines IL4 and IL5, immunoglobulins, and eosinophils. IL4 is an important mediator of Th2 cell differentiation and the activation of the class switching mechanism of B cells to produce IgE, whereas IL5 is a potent growth and survival signal for eosinophils. Eosinophils are correlated with helminth infections (215); although their protective effects are unclear $(216,217)$, in vitro studies have demonstrated helminth killing in models of Schistosoma $(218,219)$ and Strongyloides $(216)$. Yet recent efforts are finding effector mechanisms of cell mediated immunity providing protection from various helminth species. Although the Th2 response clearly drives protection in many models, several of the most promising vaccine candidates mentioned in this review tend to elicit both Th1 and Th2 arms of immunity, as summarized in Table 2.

Helminths are complicated eukaryotes which have evolved to promote regulatory $\mathrm{T}$ cell responses, dampening Th2 type immunity and allowing their chronic persistence. While vaccines may strive to boost Th2 responses, they should maintain Treg responses as regulation plays a vital role in reducing parasite driven pathology. These responses are especially important in schistosomiasis where Tregs protect from immunopathological damage (224-226).

From our review, we believe that the contribution of the type 1 response may be underappreciated and rescued by vaccines to target these worms, especially at vulnerable larval stages. In the case of Echinococcus, Th1 responses were shown to be protective (227), and in Schistosoma mouse models, IL10 and IL12 knockout mice develop unchecked Th2 responses and exhibit significant mortality in the chronic stages of infection (228).

TABLE 2 | Summary of promising helminth vaccines.

\begin{tabular}{|c|c|c|c|c|c|c|c|}
\hline Vaccine Platform & Parasite & Target Antigen & Doses & $\begin{array}{c}\text { Parasite } \\
\text { Reduction }\end{array}$ & $\begin{array}{l}\text { Animal } \\
\text { Model }\end{array}$ & Immune Skew & Ref \\
\hline Adjuvant (QuilA) & $\begin{array}{l}\text { Fasciola } \\
\text { hepatica }\end{array}$ & Cathepsin L1 mimotopes & 2 & $79.5 \%$ worms & Goats & Th1/Th2 & $(130)$ \\
\hline Adjuvant (cholera toxin B subunit) intranasal & $\begin{array}{l}\text { Trichinella } \\
\text { spiralis }\end{array}$ & Serine protease & 3 & $\begin{array}{l}71.1 \% \text { worms } \\
62.1 \% \text { muscle } \\
\text { larvae }\end{array}$ & $\begin{array}{l}\mathrm{BALB} / \mathrm{c} \\
\text { mice }\end{array}$ & $\begin{array}{l}\text { Th1/Th2/mucosal } \\
\lg \mathrm{A}\end{array}$ & $(220)$ \\
\hline Adjuvant (GLA-SE) & $\begin{array}{l}\text { Schistosoma } \\
\text { mansoni }\end{array}$ & Sm-p80 & 4 & $\begin{array}{l}65.9 \% \text { worms } \\
91.4 \% \text { liver eggs } \\
88.8 \% \text { intestinal } \\
\text { eggs }\end{array}$ & Baboons & Th2 & $(108)$ \\
\hline Adjuvant (ADAD) & $\begin{array}{l}\text { Schistosoma } \\
\text { mansoni }\end{array}$ & $\begin{array}{l}\text { B-cell epitope of Serine protease } \\
\text { inhibitor }\end{array}$ & 3 & $\begin{array}{l}89 \% \text { female } \\
\text { worms only } \\
77 \% \text { intestinal } \\
\text { eggs } \\
81 \% \text { liver eggs }\end{array}$ & $\begin{array}{l}\text { BALB/c } \\
\text { mice }\end{array}$ & Th2 & $(136)$ \\
\hline Adjuvant (AddaVax) & $\begin{array}{l}\text { Schistosoma } \\
\text { mansoni }\end{array}$ & Cathepsin B & 3 & $\begin{array}{l}86.8 \% \text { worms } \\
78 \% \text { liver eggs } \\
83.4 \% \text { intestinal } \\
\text { eggs }\end{array}$ & $\begin{array}{l}\text { C57BL/6 } \\
\text { mice }\end{array}$ & $\begin{array}{l}\text { Th1/Th2/anti- } \\
\text { inflammatory }\end{array}$ & $(133)$ \\
\hline Adjuvant (GLA-SE) & Brugia malayi & Tetravalent fusion protein & 3 & $88.1 \%$ larvae & $\begin{array}{l}\text { BALB/c } \\
\text { mice }\end{array}$ & Th1/Th2 & $(110)$ \\
\hline $\begin{array}{l}\text { DNA/Adjuvant (CpG) prime, Protein/ } \\
\text { Adjuvant (CpG) boost }\end{array}$ & Brugia malayi & Heavy chain myosin & 4 & $84.5 \%$ larvae & $\begin{array}{l}\mathrm{BALB} / \mathrm{c} \\
\text { mice }\end{array}$ & Th1 & $(221)$ \\
\hline DNA & $\begin{array}{l}\text { Trichinella } \\
\text { spiralis }\end{array}$ & Co-administered Ts43 and Ts45 & 3 & $\begin{array}{l}75.9 \% \text { muscle } \\
\text { larvae }\end{array}$ & $\begin{array}{l}\mathrm{BALB} / \mathrm{c} \\
\text { mice }\end{array}$ & Th1/Th2 & $(153)$ \\
\hline DNA & $\begin{array}{l}\text { Schistosoma } \\
\text { japonicum }\end{array}$ & $\begin{array}{l}2 \text { Co-expressed bivalent fusion } \\
\text { proteins (tetravalent) }\end{array}$ & 1 & $\begin{array}{l}70.8 \% \text { worms } \\
60.7 \% \text { liver eggs }\end{array}$ & $\begin{array}{l}\text { BALB/c } \\
\text { mice }\end{array}$ & not determined & $(222)$ \\
\hline $\begin{array}{l}\text { Adenovirus prime, Protein/Adjuvant } \\
\text { (Freund's incomplete) boost }\end{array}$ & $\begin{array}{l}\text { Schistosoma } \\
\text { japonicum }\end{array}$ & Triosephosphate isomerase & 4 & $\begin{array}{l}72.1 \% \text { worms } \\
72.1 \% \text { liver eggs }\end{array}$ & $\mathrm{BALB} / \mathrm{c}$ & Th1/Th2 & $(223)$ \\
\hline
\end{tabular}


Additionally, a key cytokine of the Th1 response, IFN $\gamma$, plays an important role in protection from filariasis (229). Although in natural infection models the immunity afforded by unspecific Th1 responses is diminutive, protection in vaccine models is more pronounced through the expansion of focused cell mediated immunity and Th1 cytokines. It is possible that a carefully balanced immune response, eliciting multiple immune mechanisms directed at vital parasitic molecules, could be the key to protection from helminthic infections.

As worms mature through multiple life cycle stages within the host it is also reasonable that these various facets of immunity can act at different points in time. Where Th2 immunity is often highly effective against adult worms, Th1 and innate immunity may better target juvenile stages of worms travelling through skin and mucosal sites. The immune system's first responder to invading pathogens is the innate immune system. The first cells to encounter helminths are macrophages, dendritic cells, and other APCs.

Besides upregulating Th2 responses and increasing IL4, IL5, and IgE, other innate immune cells which may provide direct helminth protection are neutrophils and NK cells. Neutrophil extracellular traps (NETs) are web like chromatin structures and are known to protect against large pathogens (230). Research into NETs in helminthic contexts has shown that they negatively impact the fitness of hookworm larvae after skin penetration (231). NETs are also able to trap Strongyloides larvae in vivo, potentially making them vulnerable to neutrophil, eosinophil, and macrophage killing seen in vitro (232). Neutrophils may be an interesting target for other helminths which spend time passaging through skin sites, such as Schistosoma and Onchocerca. NK cells are not well studied in helminth vaccines, and despite their relation to the innate immune system, there is evidence that these cells can be long lived and acquire antigen specific memory $(233,234)$. Although their importance to the protection of an Ostertagia cattle vaccine is unknown, this vaccine induced NK cell activation (235). These data are reminiscent of previous work using recombinant Onchocerca volvulus ASP-1 which induced a dominant IFN $\gamma$ response, likely produced by activated NK cells (236), albeit NK cells can also act through ADCC and kill via degranulation. NK cells may recognize antibody-sequestered parasite and release perforin, granzyme, and granulysin, the latter two of which are upregulated in vaccinated animals against Ostertagia (237). Helminth vaccines may work to ramp up innate immune cells, as seen in Bacille-Calmette-Guerin vaccination (238), despite their nonspecific nature.

It is difficult to concretely attribute immune effectors of helminth protection provided by vaccines, although a collection of some protective responses can be seen in Figure 3. Despite many studies seeking to identify protective mechanisms in infection models, most helminth vaccine studies give only broad descriptions of the conferred immune landscape and systemic immune cell responses after vaccination. A few groups have looked more in detail at vaccine induced immune mechanisms. However, more emphasis should be placed on immune effector knockouts and passive transfer experiments.
If we are to find the necessities for helminth protection, we must not only look at general immunogenicity but hone in on specific responses which are indispensable for helminth killing.

\section{OTHER CONSIDERATIONS}

As briefly mentioned here, targeting multiple antigens in vaccines can sometimes increase protection efficacy. In a tetravalent DNA vaccine for schistosomiasis, parasite burden was reduced by $70.8 \%$ in adult worms compared to the $52-53 \%$ worm reduction of its divalent equivalents (222). A similar bivalent DNA vaccine was tested before this. Although protection from S. japonicum reached only 58.97\% in their most effective vaccine, this group showed higher protection than that of their monovalent DNA vaccines (239). The inclusion of multiple antigens also opens an avenue for cross protection against multiple helminth species. This is increasingly tempting as many regions are co-endemic for several helminths (240). Additionally, vaccine parameters including routes of administration (IM, SC, intradermal), specific dosages (50, 100, $200 \mu \mathrm{g} /$ mouse), and different numbers of immunizations $(1,2,3)$ were tested. These parameters should be considered as each variable can change the elicited immune response (241). The importance of vaccine schedule testing is supported by a recombinant adenovirus $S$. japonicum vaccine which showed higher parasite burden reduction when administered in two doses versus three (242).

An important caveat learned from the Na-ASP-1 vaccine is the possibility of IgE hypersensitivity in individuals previously exposed to helminths. As parasitic worms are known for their Th2 and IgE responses (243), it is important to assess allergic immune responses against target antigens to avoid vaccineinduced adverse events. As seen in the case of Na-ASP-1, the cross-linking of vaccine induced antibodies with those from natural infection can lead to detrimental responses such as significant histamine release (195). Given the prevalence of helminth infections in endemic regions, it would be operationally difficult to ensure each vaccinated individual is without a potentially cross-reactive previous infection. Instead, antigens which are protective but not recognized by preexisting IgE should be considered, and vaccine candidates should be evaluated for their antigen-specific allergic-type responses.

It is an interesting idea to challenge current vaccination standards. For example, adjuvanted protein vaccines are generally administered IM or SC. However, a T. spiralis vaccine targeting a serine protease was administered intranasally with cholera toxin B subunit. This group was able to reduce parasite burden by $71.1 \%$ and observed visually shorter worms in vaccinated animals. Most notable about intranasal administration of this vaccine was, in addition to eliciting an antigen specific IgA response in the serum, it induced a systemic mucosal response generating specific IgA in the intestines (220) which may be increasingly relevant for this gut dwelling parasite. However, in the pursuit of novel approaches we must acknowledge regulatory agencies such as the FDA (USA), 


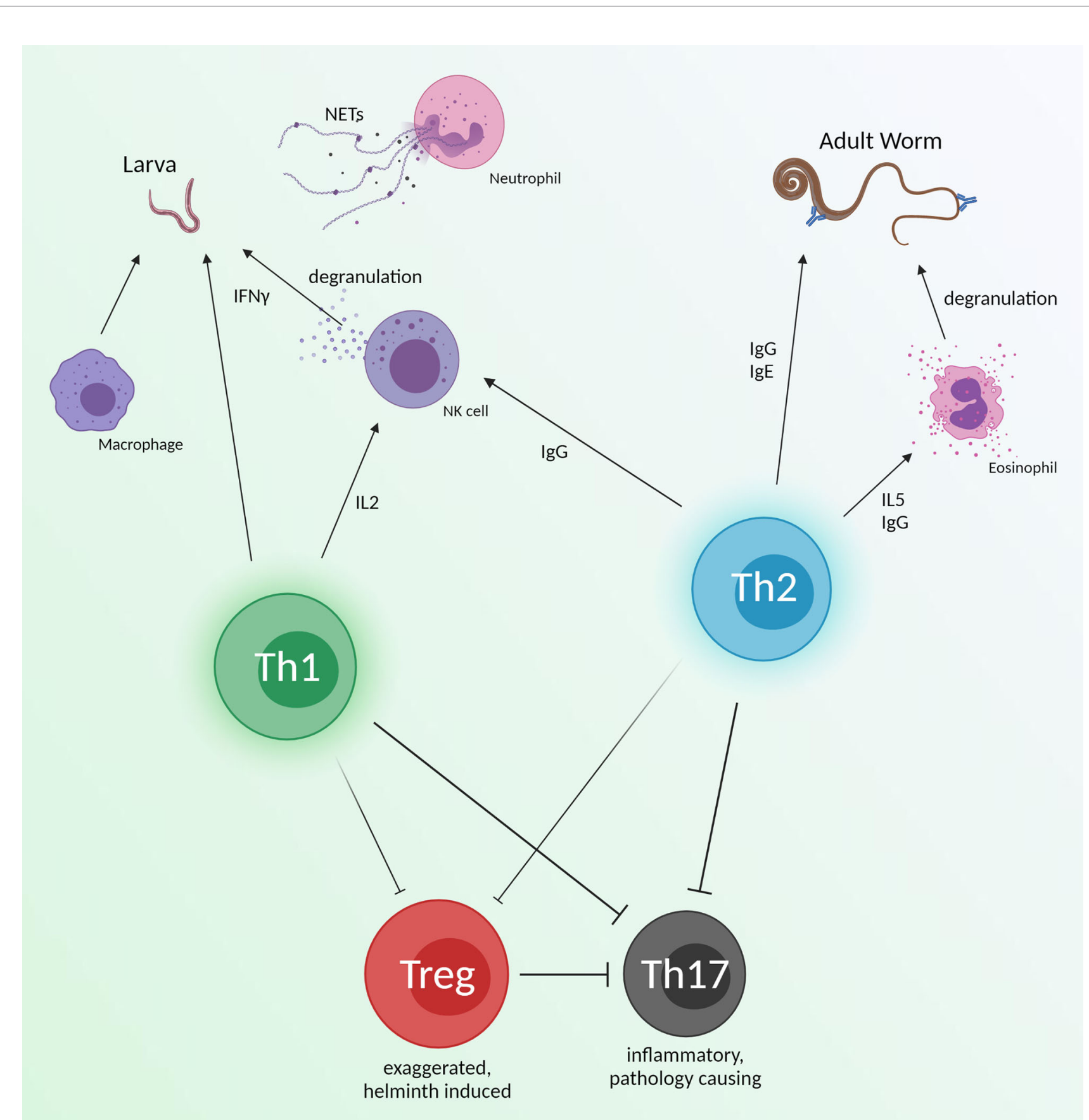

FIGURE 3 | An overview of immune effectors which have shown helminth killing. These responses are broad and could be an ideal immune response for vaccines to emulate. Th1 and Th2 responses may work synergistically with innate immunity to directly target juvenile and adult worms. Simultaneously, helminth induced Treg responses will be diminished, but still prevent inflammation from Th17 function. Created with BioRender.com.

BRDD (Canada), MHRA (UK), and EMA (EU). It would be beneficial to choose vaccine technologies which are likely to progress into human trials. For example, vaccines utilizing Freund's adjuvant are interesting as proof of concept, however they will never be progressed into clinical applications. Novel vaccine development is further complicated in the current era of vaccine hesitancy given the anti-vaccine movement.
Additionally, helminth vaccines are primarily developed for low- and middle-income countries. Although the significant portion of the world's population is at risk of helminth infection, there is very little commercial potential to develop these vaccines for a population which can't afford them. It is important to consider production costs when developing helminth vaccines since these infections lack the financial 
incentive which surrounds many other infectious diseases (i.e.: HIV/AIDS, COVID-19).

\section{CONCLUSION}

By no means are the platforms discussed here an exhaustive list of those in development for helminth vaccines. In recent years there have been many others employed including: nanoparticles (244), virus-like particles (245), plant-based vaccines (246), as well as bacterial vectored vaccines similar to our own effort (247).

During the vaccine development process, we propose to follow the path described in Figure 4. Determining the most effective platform for helminth vaccination is a convoluted question as each has been shown to have protective efficacy in different models. Instead we suggest researchers start by determining the protective correlates of immunity associated with the targeted helminth(s).
Once an antigen is determined, by assessing its necessity to parasite survival and protective efficacy, a novel vaccine platform can be utilized to induce or increase protection.

Each vaccine platform discussed brings forth its own set of positive and negative attributes, each of them when combined with an antigen may elicit unique features of the immune system. Some commonly observed advantages and disadvantages of the platforms discussed are described in Table 3, considering each platform independently. Adjuvanted recombinant protein vaccines are well studied and have been shown to be highly effective in animal models. However, recombinant protein expression systems and adjuvants can be expensive, which may not be ideal for a vaccine that is geared for use in the global South. With the authorization of vaccines utilizing mRNA-based and viral vectored technology catalyzed by the 2019 coronavirus pandemic, new avenues of vaccine development have been opened, ones which are arguably easier to develop and more

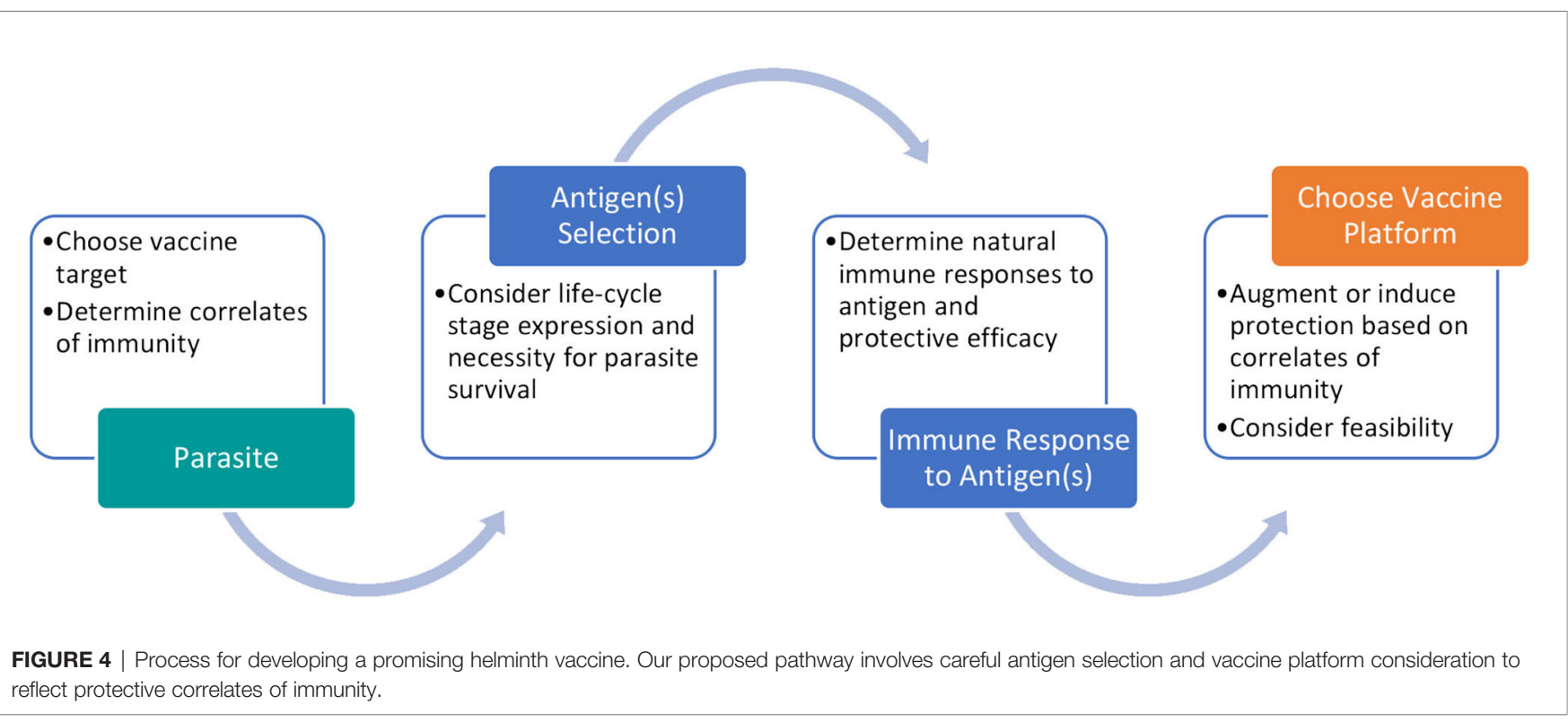

TABLE 3 | Advantages and disadvantages of various vaccine platforms.

\begin{tabular}{|c|c|c|c|}
\hline Vaccine Platform & Advantages & Disadvantages & Key Features \\
\hline Irradiated Parasite & $\begin{array}{l}\text { - Strong protection, especially with increasing } \\
\text { doses }\end{array}$ & $\begin{array}{l}\text { - Heterogenous vaccine } \\
\text { - Parasite life-cycle dependent for } \\
\text { development } \\
\text { Unethical as some parasite may } \\
\text { mature to adult stage }\end{array}$ & - Mimic natural infection \\
\hline Adjuvanted Protein & $\begin{array}{l}\text { - Various adjuvants will give different immune } \\
\text { responses } \\
\text { - Shown to be effective } \\
\text { - Can be used in populations with weakened } \\
\text { immune systems }\end{array}$ & - Can be expensive to produce & $\begin{array}{l}\text { - Immune response varies depending } \\
\text { on adjuvant used }\end{array}$ \\
\hline $\begin{array}{l}\text { Nucleic Acid (DNA } \\
\text { based) }\end{array}$ & $\begin{array}{l}\text { - } \quad \text { Quick and simple design } \\
\text { - } \quad \text { Thermostable } \\
\text { - } \quad \text { Cost effective }\end{array}$ & $\begin{array}{l}\text { - } \quad \text { Low immunogenicity in humans } \\
\text { - } \quad \text { Enters host cell nucleus }\end{array}$ & - Mostly cell mediated immune responses \\
\hline Viral Vectored & $\begin{array}{l}\text { - } \quad \text { Specific delivery of antigen to target cells } \\
\text { - } \quad \text { High antigen expression } \\
\text { - } \quad \text { Gene expression can be short or long term }\end{array}$ & $\begin{array}{ll}\text { - } & \text { Neutralizing immunity } \\
\text { - } & \text { Off target virus shedding }\end{array}$ & $\begin{array}{ll}\text { - } & \text { Humoral responses } \\
\text { - } & \text { CD8+ T cell responses } \\
\text { - } & \text { Th1 dominant CD4+ T cell responses }\end{array}$ \\
\hline
\end{tabular}


cost-effective. To ameliorate disadvantages in these platforms some groups have employed heterologous prime boost strategies to help carve a desired immunotype, thereby increasing protective responses. To this end, there is a solid foundation to explore novel vaccination strategies.

Helminths have evolved with humans and in this time have developed ingenious methods of evading our immune response. To create an effective, protective response against helminths we must counteract these evasion mechanisms by developing vaccines which harness correlates of immunity. There has yet to be a human helminth vaccine approved by any regulatory agency but considering the constructs currently in clinical trials and the promising vaccines in preclinical development, this may change in the near future.

\section{REFERENCES}

1. Centers for Disease Control and Prevention. Neglected Tropical Diseases (NTDs). Available at: https://www.cdc.gov/globalhealth/newsroom/topics/ ntds/ index.html. (2018). (Accessed March 22, 2021).

2. Hotez PJ, Brindley PJ, Bethony JM, King CH, Pearce EJ, Jacobson J. Helminth Infections: The Great Neglected Tropical Diseases. J Clin Invest (2008) 118(4):1311-21. doi: 10.1172/JCI34261

3. World Health Organization. Helminthiasis. (2021). Available at: https:// www.afro.who.int/health-topics/helminthiasis. (Accessed July 13, 2021).

4. Cox FEG. History of Human Parasitology. Clin Microbiol Rev (2002) 15:595-612. doi: 10.1128/CMR.15.4.595-612.2002

5. Smith HV, Girdwood T. The Parasites of Homo Sapiens by R.W. Ashford and W. Crewe. Parasitol Today (1999) 15(12):510. doi: 10.1016/S0169-4758 (99)01572-0

6. McSorley HJ, Maizels RM. Helminth Infections and Host Immune Regulation. Clin Microbiol Rev (2012) 25(4):585-608. doi: 10.1128/ CMR.05040-11

7. Ferreira MU, Crainey JL, Luz SLB. Mansonella Ozzardi. Trends Parasitol (2021) 37:90-1. doi: 10.1016/j.pt.2020.03.005

8. Hartmann W, Brunn ML, Stetter N, Gagliani N, Muscate F, StanelleBertram S, et al. Helminth Infections Suppress the Efficacy of Vaccination Against Seasonal Influenza. Cell Rep (2019) 29(8):2243-2256.e4. doi: 10.1016/j.celrep.2019.10.051

9. Dzhivhuho GA, Rehrl SA, Ndlovu H, Horsnell WGC, Brombacher F, Williamson A-L, et al. Chronic Schistosomiasis Suppresses HIV-Specific Responses to DNA-MVA and MVA-Gp140 Env Vaccine Regimens Despite Antihelminthic Treatment and Increases Helminth-Associated Pathology in a Mouse Model. PloS Pathog (2018) 14(7):e1007182. doi: 10.1371/ journal.ppat.1007182

10. Kroidl I, Saathoff E, Maganga L, Makunde WH, Hoerauf A, Geldmacher C, et al. Effect of Wuchereria Bancrofti Infection on HIV Incidence in Southwest Tanzania: A Prospective Cohort Study. Lancet (2016) 388 (10054):1912-20. doi: 10.1016/S0140-6736(16)31252-1

11. Hotez PJ, Harrison W, Fenwick A, Bustinduy AL, Ducker C, Mbabazi PS, et al. Female Genital Schistosomiasis and HIV/AIDS: Reversing the Neglect of Girls and Women. PloS Neglect Trop Dis (2019) 13:e0007025. doi: 10.1371/journal.pntd.0007025

12. Midzi N, Sangweme D, Zinyowera S, Mapingure MP, Brouwer KC, Munatsi A, et al. The Burden of Polyparasitism Among Primary Schoolchildren in Rural and Farming Areas in Zimbabwe. Trans R Soc Trop Med Hyg (2008) 102(10):1039-45. doi: 10.1016/j.trstmh.2008.05.024

13. Fernández-Niño JA, Niño N, Idrovo AJ, Cucunubá ZM, Reyes-Harker P, Guerra ÁP, et al. Paradoxical Associations Between Soil-Transmitted Helminths and Plasmodium Falciparum Infection. Trans $R$ Soc Trop Med Hyg (2012) 106(11):701-8. doi: 10.1016/j.trstmh.2012.07.012

14. Sripa B, Tangkawattana S, Brindley PJ. Update on Pathogenesis of Opisthorchiasis and Cholangiocarcinoma. Adv Parasitol (2018) 102:97113. doi: 10.1016/bs.apar.2018.10.001

15. Sripa B, Brindley PJ, Mulvenna J, Laha T, Smout MJ, Mairiang E, et al. The Tumorigenic Liver Fluke Opisthorchis Viverrini - Multiple Pathways

\section{AUTHOR CONTRIBUTIONS}

This review was written by DP and edited by MN. All authors contributed to the article and approved the submitted version.

\section{FUNDING}

This work was supported by grants provided by the Public Health Agency of Canada, Canadian Institutes of Health Research (FBD-175968), and the Foundation of the McGill University Health Centre.

to Cancer. Trends Parasitol (2012) 28:395-407. doi: 10.1016/ j.pt.2012.07.006

16. Malats N, Real FX. Epidemiology of Bladder Cancer. Hematol/Oncol Clinics North America (2015) 29:177-89. doi: 10.1016/j.hoc.2014.10.001

17. Brindley PJ, Loukas A. Helminth Infection-Induced Malignancy. PloS Pathog (2017) 13(7):e1006393. doi: 10.1371/journal.ppat.1006393

18. Gad A, Tanaka E, Orii K, Rokuhara A, Nooman Z, Serwah AH, et al. Relationship Between Hepatitis C Virus Infection and Schistosomal Liver Disease: Not Simply an Additive Effect. J Gastroenterol (2001) 36:753-8. doi: 10.1007/s005350170017

19. Rajamanickam A, Munisankar S, Dolla C, Menon PA, Nutman TB, Babu S. Helminth Coinfection Alters Monocyte Activation, Polarization, and Function in Latent Mycobacterium Tuberculosis Infection. J Immunol (2020) 204(5):1274-86. doi: 10.4049/jimmunol.1901127

20. Dykie A, Wijesinghe T, Rabson AB, Madugula K, Farinas C, Wilson S, et al. Human T-Cell Leukemia Virus Type 1 and Strongyloides Stercoralis: Partners in Pathogenesis. Pathog (2020) 9:904. doi: 10.3390/ pathogens 9110904

21. Zeng XJ, Jiang WS, Xie SY, Chen YD, Gu XN, Ge J, et al. Effect of Integrated Control Intervention on Soil-Transmitted Helminth Infections in Jiangxi Province in Southeast China. Acta Trop (2019) 194:148-54. doi: 10.1016/ j.actatropica.2019.04.001

22. Rojanapanus S, Toothong T, Boondej P, Thammapalo S, Khuanyoung N, Santabutr W, et al. How Thailand Eliminated Lymphatic Filariasis as a Public Health Problem. Infect Dis Poverty (2019) 8(1):1-15. doi: 10.1186/ s40249-019-0549-1

23. Bah YM, Paye J, Bah MS, Conteh A, Redwood-Sawyerr V, Sonnie M, et al. Achievements and Challenges of Lymphatic Filariasis Elimination in Sierra Leone. PloS Negl Trop Dis (2020) 14(12):1-16. doi: 10.1371/journal.pntd.0008877

24. Chiamah O, Ubachukwu P, Anorue C, Ebi S. Urinary Schistosomiasis in Ebonyi State, Nigeria From 2006 to 2017. J Vector Borne Dis (2019) 56:8791. doi: $10.4103 / 0972-9062.263721$

25. Weatherhead JE, Hotez PJ, Mejia R. The Global State of Helminth Control and Elimination in Children. Pediatr Clinics North America (2017) 64:86777. doi: $10.1016 /$ j.pcl.2017.03.005

26. Geerts S, Gryseels B. Anthelmintic Resistance in Human Helminths: A Review. Trop Med Int Health (2001) 6:915-21. doi: 10.1046/j.13653156.2001.00774.x

27. Vale N, Gouveia MJ, Rinaldi G, Brindley PJ, Gärtner F, Da Costa JMC. Praziquantel for Schistosomiasis: Single-Drug Metabolism Revisited, Mode of Action, and Resistance. Antimicrob Agents Chemother (2017) 61:e0258216. doi: 10.1128/AAC.02582-16

28. Biswas G, Sankara DP, Agua-Agum J, Maiga A. Dracunculiasis (Guinea Worm Disease): Eradication Without a Drug or a Vaccine. Philos Trans $R$ Soc B: Biol Sci (2013) 368:20120146. doi: 10.1098/rstb.2012.0146

29. World Health Organization. Dracunculiasis Eradication: Global Surveillance Summary, 2020. Available at: https:/www.who.int/publications/i/item/whower9621-173-194 (Accessed July 13, 2021).

30. Rauch S, Jasny E, Schmidt KE, Petsch B. New Vaccine Technologies to Combat Outbreak Situations. Front Immunol (2018) 9:1963. doi: 10.3389/ fimmu.2018.01963 
31. Zarowiecki M, Berriman M. What Helminth Genomes Have Taught Us About Parasite Evolution. Parasitology (2015) 142:S85-97. doi: 10.1017/ S0031182014001449

32. Ravindran B, Satapathy AK, Sahoo PK, Mohanty MC. Protective Immunity in Human Lymphatic Filariasis: Problems and Prospects. Med Microbiol Immunol (2003) 192:41-6. doi: 10.1007/s00430-002-0157-7

33. Kwarteng A, Ahuno ST. Immunity in Filarial Infections: Lessons From Animal Models and Human Studies. Wiley Online Libr (2017) 85(4):251-7. doi: $10.1111 /$ sji.12533

34. Karanja DM, Hightower AW, Colley DG, Mwinzi PN, Galil K, Andove J, et al. Resistance to Reinfection With Schistosoma mansoni in Occupationally Exposed Adults and Effect of HIV-1 Co-Infection on Susceptibility to Schistosomiasis: A Longitudinal Study. Lancet (2002) 360(9333):592-6. doi: 10.1016/S0140-6736(02)09781-7

35. Colley DG, Secor WE. Immunology of Human Schistosomiasis. Parasite Immunol (2014) 36(8):347-57. doi: 10.1111/pim.12087

36. Dixon JB. Echinococcosis. Comp Immunol Microbiol Infect Dis (1997) 20 (1):87-94. doi: 10.1016/S0147-9571(96)00019-7

37. Smithers SR, Terry RJ. Immunity in Schistosomiasis. Ann N Y Acad Sci (1969) 160(2):826-40. doi: 10.1111/j.1749-6632.1969.tb15904.x

38. Tawfik AF, Colley DG. Effects of Anti-Schistosomal Chemotherapy on Immune Responses, Protection and Immunity. II. Concomitant Immunity and Immunization With Irradiated Cercariae. Am J Trop Med Hyg (1986) 35 (1):110-7. doi: 10.4269/ajtmh.1986.35.110

39. Buck JC, De Leo GA, Sokolow SH. Concomitant Immunity and Worm Senescence May Drive Schistosomiasis Epidemiological Patterns: An EcoEvolutionary Perspective. Front Immunol (2020) 11:160. doi: 10.3389/ fimmu.2020.00160/full

40. Ploeger HW, Eysker M. Protection Against and Establishment of Dictyocaulus Viviparus Following Primary Infection at Different Dose Levels. Vet Parasitol (2002) 106(3):213-23. doi: 10.1016/s0304-4017(02)00082-1

41. Taylor SM, Kenny J, Edgar HW, Mallon TR, Canavan A. Induction of Protective Immunity to Dictyocaulus Viviparus in Calves While Under Treatment With Endectocides. Vet Parasitol (2000) 88(3-4):219-28. doi: 10.1016/s0304-4017(99)00216-2

42. Morris CP, Evans H, Larsen SE, Mitre E. A Comprehensive, Model-Based Review of Vaccine and Repeat Infection Trials for Filariasis. Am Soc Microbiol (2013) 26(3):381-421. doi: 10.1128/CMR.00002-13

43. Haque A, Chassoux D, Capron A, Ogilvie BM. Dipetalonema Viteae Infection in Hamsters: Enhancement and Suppression of Microfilaraemia. Parasitology (1978) 76(1):77-84. doi: 10.1017/S0031182000047405

44. Rajakumar S, Bleiss W, Hartmann S, Schierack P, Marko A, Lucius R. Concomitant Immunity in a Rodent Model of Filariasis: The Infection of Meriones Unguiculatus With Acanthocheilonema Viteae. J Parasitol (2006) 92(1):41-5. doi: 10.1645/GE-3507.1

45. Claerebout E, Geldhof P. Helminth Vaccines in Ruminants: From Development to Application. Vet Clinics North America - Food Anim Pract (2020) 36p:159-71. doi: 10.1016/j.cvfa.2019.10.001

46. Gause WC, Rothlin C, Loke P. Heterogeneity in the Initiation, Development and Function of Type 2 Immunity. Nat Rev Immunol Nat Res (2020) 20:60314. doi: 10.1038/s41577-020-0301-x

47. Turner JD, Faulkner H, Kamgno J, Kennedy MW, Behnke J, Boussinesq M, et al. Allergen-Specific IgE and IgG4 Are Markers of Resistance and Susceptibility in a Human Intestinal Nematode Infection. Microbes Infect (2005) 7(7-8):990-6. doi: 10.1016/j.micinf.2005.03.036

48. Medhat A, Shehata M, Bucci K, Mohamed S, Dief ADE, Badary S, et al. Increased Interleukin-4 and Interleukin-5 Production in Response to Schistosoma Haematobium Adult Worm Antigens Correlates With Lack of Reinfection After Treatment. J Infect Dis (1998) 178(2):512-9. doi: 10.1086/515630

49. Yasuda K, Kuroda E. Role of Eosinophils in Protective Immunity Against Secondary Nematode Infections. Immunol Med (2019) 42:148-55. doi: 10.1080/25785826.2019.1697135

50. Herbert DR, Douglas B, Zullo K. Group 2 Innate Lymphoid Cells (ILC2): Type 2 Immunity and Helminth Immunity. Int J Mol Sci (2019) 20(9):2276. doi: 10.3390/ijms20092276

51. Fitzsimmons CM, Falcone FH, Dunne DW. Helminth Allergens, ParasiteSpecific IgE, and Its Protective Role in Human Immunity. Front Immunol (2014) 5:61. doi: 10.3389/fimmu.2014.00061
52. Turner J, Faulkner H, Kamgno J, Else K, Boussinesq M, Bradley JE. A Comparison of Cellular and Humoral Immune Responses to Trichuroid Derived Antigens in Human Trichuriasis. Parasite Immunol (2002) 24 (2):83-93. doi: 10.1046/j.0141-9838.2001.00442.x

53. Muhsin M, Ajendra J, Gentil K, Berbudi A, Neumann AL, Klaas L, et al. IL-6 Is Required for Protective Immune Responses Against Early Filarial Infection. Int J Parasitol (2018) 48(12):925-35. doi: 10.1016/j.ijpara. 2018.05.011

54. Faulkner H, Turner J, Kamgno J, Pion SD, Boussinesq M, Bradley JE. Ageand Infection Intensity-Dependent Cytokine and Antibody Production in Human Trichuriasis: The Importance of IgE. J Infect Dis (2002) 185(5):66572. doi: $10.1086 / 339005$

55. Layland LE, Mages J, Loddenkemper C, Hoerauf A, Wagner H, Lang R, et al. Pronounced Phenotype in Activated Regulatory T Cells During a Chronic Helminth Infection. J Immunol (2010) 184(2):713-24. doi: 10.4049/ jimmunol.0901435

56. Babu S, Nutman TB. Immunology of Lymphatic Filariasis. Parasite Immunol (2014) 36:338-46. doi: 10.1111/pim.12081

57. Cooper PJ, Figuieredo CA. Immunology of Ascaris and Immunomodulation. In: Ascaris: The Neglected Parasite. Elsevier Inc (2013). p. 3-19.

58. Yong L, Tang Y, Ren C, Liu M, Shen J, Hou X. B1 Cells Protect Against Schistosoma Japonicum-Induced Liver Inflammation and Fibrosis by Controlling Monocyte Infiltration. PloS Negl Trop Dis (2019) 13(6): e0007474. doi: 10.1371/journal.pntd.0007474

59. Maizels RM, McSorley HJ. Regulation of the Host Immune System by Helminth Parasites. J Allergy Clin Immunol (2016) 138(3):666-75. doi: 10.1016/j.jaci.2016.07.007

60. Zakeri A, Hansen EP, Andersen SD, Williams AR, Nejsum P. Immunomodulation by Helminths: Intracellular Pathways and Extracellular Vesicles. Front Immunol (2018) 9:2349. doi: 10.3389/ fimmu.2018.02349

61. Soloviova K, Fox EC, Dalton JP, Caffrey CR, Davies SJ. A Secreted Schistosome Cathepsin B1 Cysteine Protease and Acute Schistosome Infection Induce a Transient T Helper 17 Response. PloS Negl Trop Dis (2019) 13(1):e0007070. doi: 10.1371/journal.pntd.0007070

62. Zhang S. The Role of Transforming Growth Factor $\beta$ in T Helper 17 Differentiation. Immunology (2018) 155:24-35. doi: 10.1111/imm.12938

63. Wong MM, Fredericks HJ, Ramachandran CP. Studies on Immunization Against Brugia Malayi Infection in the Rhesus Monkey. Bull World Health Org (1969) 40(4):493-501.

64. Schrempf-Eppstein B, Kern A, Textor G, Lucius R. Acanthocheilonema Viteae: Vaccination With Irradiated L3 Induces Resistance in Three Species of Rodents (Meriones Unguiculatus, Mastomys Coucha, Mesocricetus Auratus). Trop Med Int Heal (1997) 2(1):104-10. doi: 10.1046/j.13653156.1997.d01-129.x

65. Babayan SA, Attout T, Harris A, Taylor MD, Le Goff L, Vuong PN, et al. Vaccination Against Filarial Nematodes With Irradiated Larvae Provides Long-Term Protection Against the Third Larval Stage But Not Against Subsequent Life Cycle Stages. Int J Parasitol (2006) 36(8):903-14. doi: 10.1016/j.ijpara.2006.04.013

66. Torrero MN, Morris CP, Mitre BK, Hübner MP, Fox EM, Karasuyama H, et al. Basophils Help Establish Protective Immunity Induced by Irradiated Larval Vaccination for Filariasis. Vaccine (2013) 31(36):3675-82. doi: 10.1016/j.vaccine.2013.06.010

67. Hafeez M, Rao BV. Studies on Amphistomiasis in Andhra Pradesh (India) VI. Immunization of Lambs and Kids With Gamma Irradiated Metacereariae of Cercariae Indicae XXVI. J Helminthol (1981) 55(1):2932. doi: 10.1017/S0022149X00025426

68. Urban JF, Tromba FG. Development of Immune Responsiveness to Ascaris Suum Antigens in Pigs Vaccinated With Ultraviolet-Attenuated Eggs. Vet Immunol Immunopathol (1982) 3(4):399-409. doi: 10.1016/0165-2427(82) 90022-8

69. Tromba FG. Immunization of Pigs Against Experimental Ascaris Suum Infection by Feeding Ultraviolet-Attenuated Eggs. J Parasitol (1978) 64 (4):651-6. doi: 10.2307/3279954

70. Jian X, Jun-Min Y, Hai-Chou X, Hui-Qing Q, Hai-Nan R, Hotez P, et al. Protective Immunity Elicited By Ultraviolet-Irradiated Third-Stage Infective Hookworm (Necator Americanus And Ancylostoma Caninum) Larvae In 
Mice And Hamsters. Southeast Asian J Trop Med Public Health (2006) 37 (5):885-95.

71. Conder GA, Williams JF. Immunization With Infective Larvae of Strongyloides Ratti (Nematoda) Exposed to Microwave Radiation. J Parasitol (1983) 69(1):83-7. doi: 10.2307/3281280

72. Boag PR, Parsons JC, Presidente PJA, Spithill TW, Sexton JL. Characterisation of Humoral Immune Responses in Dogs Vaccinated With Irradiated Ancylostoma Caninum. Vet Immunol Immunopathol (2003) 92(1-2):87-94. doi: 10.1016/S0165-2427(03)00006-0

73. Fujiwara RT, Loukas A, Mendez S, Williamson AL, Bueno LL, Wang Y, et al. Vaccination With Irradiated Ancylostoma Caninum Third Stage Larvae Induces a Th2 Protective Response in Dogs. Vaccine (2006) 24(4):501-9. doi: 10.1016/j.vaccine.2005.07.091

74. Creaney J, Wilson L, Dosen M, Mark Sandeman R, Spithill TW, Parsons JC. Fasciola Hepatica: Irradiation-Induced Alterations in Carbohydrate and Cathepsin-B Protease Expression in Newly Excysted Juvenile Liver Fluke. Exp Parasitol (1996) 83(2):202-15. doi: 10.1006/expr.1996.0067

75. Creaney J, Spithill TW, Thompson CM, Wilson LR, Sandeman RM, Parsons JC. Attempted Immunisation of Sheep Against Fasciola Hepatica Using $\gamma$ Irradiated Metacercariae. Int J Parasitol (1995) 25(7):853-6. doi: 10.1016/ 0020-7519(94)00204-2

76. Nansen P. Resistance in Cattle to Fasciola Hepatica Induced by $\gamma$ Ray Attenuated Larvae: Results From a Controlled Field Trial. Res Vet Sci (1975) 19(3):278-83. doi: 10.1016/S0034-5288(18)33502-1

77. Younis SA, Yagi AI, Haroun EM, Gameel AA, Taylor MG. Immunization of Zebu Calves Against Fasciola Gigantica, Using Irradiated Metacercariae. J Helminthol (1986) 60(2):123-34. doi: 10.1017/S0022149X0000835X

78. Hafez EN, Hafez MN, Amin MM. Effect of Vaccination With Irradiated Toxocara Canis Larvae or Thyme Oil Treatment on Testicular Histochemical and Immunohistochemical Changes of Rats. Trop BioMed (2019) 36(2):430-42.

79. Hafez EN, Awadallah FM, Ibrahim SA, Amin MM, El-Nawasera NZ. Assessment of Vaccination With Gamma Radiation-Attenuated Infective Toxocara Canis Eggs on Murine Toxocariasis. Trop BioMed (2020) 37(1):89-102.

80. Nakayama $H$, Inaba $T$, Nargis $M$, Chisty $M M$, Ito $M$, Kamiya $H$. Immunization of Laboratory Animals With Ultraviolet-Attenuated Larvae Against Homologous Challenge Infection With Trichinella Britovi. Southeast Asian J Trop Med Public Health (1998) 29(3):563-6.

81. Ali SM, El-Zawawy LA, El-Said D, Gaafar MR. Immunization Against Trichinellosis Using Microwaved Larvae of Trichinela Spiralis. J Egypt Soc Parasitol (2007) 37(1):121-33.

82. Lange AM, Yutanawiboonchai W, Lok JB, Trpis M, Abraham D. Induction of Protective Immunity Against Larval Onchocerca Volvulus in a Mouse Model. Am J Trop Med Hyg (1993) 49(6):783-8. doi: 10.4269/ajtmh. 1993.49.783

83. Taylor MJ, Van Es RP, Shay K, Folkard SG, Townson S, Bianco AE. Protective Immunity Against Onchocerca Volvulus and O. Lienalis Infective Larvae in Mice. Trop Med Parasitol (1994) 45(1):17-23.

84. Prince AM, Brotman B, Johnson EH, Smith A, Pascual D, Lustigman S. Onchocerca Volvulus: Immunization of Chimpanzees With X-Irradiated Third-Stage (L3) Larvae. Exp Parasitol (1992) 74(3):239-50. doi: 10.1016/ 0014-4894(92)90147-3

85. Fu SQ, Lee JB, Jun SB, Ohwatari N, Young KM, Hun MY. Resistance to Reinfection in Rats Induced by Irradiated Metacercariae of Clonorchis Sinensis. Mem Inst Oswaldo Cruz (2005) 100(5):549-54. doi: 10.1590/ S0074-02762005000500016

86. Movsesijan M, Sokolic A, Mladenović Z. Studies on the Immunological Potentiality of Irradiated Echinococcus Granulosus Forms: Immunization Experiments in Dogs. Br Vet J (1968) 124(10):425-8. doi: 10.1016/S00071935(17)39151-0

87. Smithers SR. Immunizing Effect of Irradiated Cercariæ of Schistosoma Mansoni in Rhesus Monkeys. Nature (1962) 194(4834):1146-7. doi: $10.1038 / 1941146 a 0$

88. Stek M, Minard P, Dean DA, Hall JE. Immunization of Baboons With Schistosoma mansoni Cercariae Attenuated By Gamma Irradiation. Science (1981) 212(4502):1518-20. doi: 10.1126/science.7233238

89. Kariuki TM, Farah IO, Yole DS, Mwenda JM, Van Dam GJ, Deelder AM, et al. Parameters of the Attenuated Schistosome Vaccine Evaluated in the
Olive Baboon. Infect Immun (2004) 72(9):5526-9. doi: 10.1128/ IAI.72.9.5526-5529.2004

90. Hsü HF, Hsü SYL, Osborne JW. Immunization Against Schistosoma Japonicum in Rhesus Monkeys Produced by Irradiated Cercariæ. Nature (1962) 194(4823):98-9. doi: 10.1038/194098a0

91. Lin D, Tian F, Wu H, Gao Y, Wu J, Zhang D, et al. Multiple Vaccinations With UV- Attenuated Cercariae in Pig Enhance Protective Immunity Against Schistosoma Japonicum Infection as Compared to Single Vaccination. Parasites Vectors (2011) 4(1):103. doi: 10.1186/1756-3305-4-103

92. Webbe G, Sturrock RF, James ER, James C. Schistosoma Haematobium in the Baboon (Papio Anubis): Effect of Vaccination With Irradiated Larvae on the Subsequent Infection With Percutaneously Applied Cercariae. Trans $R$ Soc Trop Med Hyg (1982) 76(3):354-61. doi: 10.1016/0035-9203(82)90189-4

93. Agnew AM, Murare HM, Doenhoff MJ. Specific Cross-Protection Between Schistosoma Bovis and S. Haematobium Induced by Highly Irradiated Infections in Mice. Paiasitr Immunol (1989) 11(4):341-9. doi: 10.1111/j.13653024.1989.tb00672.x

94. Dean DA, Mangold BL, Harrison RA, Ricciardone MD. Homologous and Heterologous Protective Immunity to Egyptian Strains of Schistosoma Mansoni and S. Haematobium Induced by Ultraviolet-Irradiated Cercariae. Parasite Immunol (1996) 18(8):403-10. doi: 10.1046/j.13653024.1996.d01-129.x

95. Harrison RA, Bickle QD, Kiare S, James ER, Andrews BJ, Sturrock RF, et al. Immunization of Baboons With Attenuated Schistosomula of Schistosoma Haematobium: Levels of Protection Induced by Immunization With Larvae Irradiated With 20 and 60 Krad. Trans R Soc Trop Med Hyg (1990) 84(1):8999. doi: 10.1016/0035-9203(90)90393-S

96. Smythies LE, Coulson PS, Wilson RA. Monoclonal Antibody to IFNGamma Modifies Pulmonary Inflammatory Responses and Abrogates Immunity to Schistosoma Mansoni in Mice Vaccinated With Attenuated Cercariae. J Immunol (1992) 149(11):3654-8.

97. Wilson RA, Coulson PS, Betts C, Dowling MA, Smythies LE. Impaired Immunity and Altered Pulmonary Responses in Mice With a Disrupted Interferon- $\gamma$ Receptor Gene Exposed to the Irradiated Schistosoma Mansoni Vaccine. Immunology (1996) 87(2):275-82. doi: 10.1046/j.1365-2567. 1996.465550.x

98. Wynn TA, Oswald IP, Eltoum IA, Caspar P, Lowenstein CJ, Lewis FA, et al. Elevated Expression of Th1 Cytokines and Nitric Oxide Synthase in the Lungs of Vaccinated Mice After Challenge Infection With Schistosoma Mansoni. J Immunol (1994) 153(11):5200-9.

99. Jankovic D, Wynn TA, Kullberg MC, Hieny S, Caspar P, James S, et al. Optimal Vaccination Against Schistosoma Mansoni Requires the Induction of Both B Cell- and IFN-Gamma-Dependent Effector Mechanisms. J Immunol (1999) 162(1):345-51.

100. Hewitson JP, Hamblin PA, Mountford AP. Immunity Induced by the Radiation-Attenuated Schistosome Vaccine. Parasite Immunol (2005) 27 (7-8):271-80. doi: 10.1111/j.1365-3024.2005.00764.x

101. Vaccine Types | NIH: National Institute of Allergy and Infectious Diseases (2021). Available at: https://www.niaid.nih.gov/research/vaccine-types.

102. Kalita P, Lyngdoh DL, Padhi AK, Shukla H, Tripathi T. Development of Multi-Epitope Driven Subunit Vaccine Against Fasciola Gigantica Using Immunoinformatics Approach. Int J Biol Macromol (2019) 138:224-33. doi: 10.1016/j.ijbiomac.2019.07.024

103. Sanches RCO, Tiwari S, Ferreira LCG, Oliveira FM, Lopes MD, Passos MJF, et al. Immunoinformatics Design of Multi-Epitope Peptide-Based Vaccine Against Schistosoma Mansoni Using Transmembrane Proteins as a Target. Front Immunol (2021) 12:621706. doi: 10.3389/fimmu.2021.621706

104. Zawawi A, Forman R, Smith H, Mair I, Jibril M, Albaqshi MH, et al. In Silico Design of a T-Cell Epitope Vaccine Candidate for Parasitic Helminth Infection. PloS Pathog (2020) 16(3):e1008243. doi: 10.1371/journal.ppat.1008243

105. Jain S, George PJ, Deng W, Koussa J, Parkhouse K, Hensley SE, et al. The Parasite-Derived rOv-ASP-1 Is an Effective Antigen-Sparing CD4+ T CellDependent Adjuvant for the Trivalent Inactivated Influenza Vaccine, and Functions in the Absence of MyD88 Pathway. Vaccine (2018) 36(25):365065. doi: 10.1016/j.vaccine.2018.05.029

106. El Ridi R, Tallima H, Selim S, Donnelly S, Cotton S, Santana BG, et al. Cysteine Peptidases as Schistosomiasis Vaccines With Inbuilt Adjuvanticity. PloS One (2014) 9(1):e85401. doi: 10.1371/journal.pone.0085401 
107. Centers for Disease Control and Prevention. (2020). Adjuvants and Vaccines. Available at: https://www.cdc.gov/vaccinesafety/concerns/adjuvants.html. (Accessed March 22, 2021).

108. Zhang W, Molehin AJ, Rojo JU, Sudduth J, Ganapathy PK, Kim E, et al. SmP80-Based Schistosomiasis Vaccine: Double-Blind Preclinical Trial in Baboons Demonstrates Comprehensive Prophylactic and Parasite Transmission-Blocking Efficacy. Ann NY Acad Sci (2018) 1425(1):38-51. doi: $10.1111 /$ nyas.13942

109. Mo AX, Colley DG. Workshop Report: Schistosomiasis Vaccine Clinical Development and Product Characteristics. Vaccine (2016) 34:995-1001. doi: 10.1016/j.vaccine.2015.12.032

110. Chauhan N, Khatri V, Banerjee P, Kalyanasundaram R. Evaluating the Vaccine Potential of a Tetravalent Fusion Protein (Rbmhaxt) Vaccine Antigen Against Lymphatic Filariasis in a Mouse Model. Front Immunol (2018) 9:1520. doi: 10.3389/fimmu.2018.01520

111. Khatri V, Chauhan N, Vishnoi K, von Gegerfelt A, Gittens C, Kalyanasundaram R. Prospects of Developing a Prophylactic Vaccine Against Human Lymphatic Filariasis - Evaluation of Protection in NonHuman Primates. Int J Parasitol (2018) 48(9-10):773-83. doi: 10.1016/ j.ijpara.2018.04.002

112. Ricciardi A, Zelt NH, Visitsunthorn K, Dalton JP, Ndao M. Immune Mechanisms Involved in Schistosoma Mansoni-Cathepsin B Vaccine Induced Protection in Mice. Front Immunol (2018) 9:1710. doi: 10.3389/ fimmu.2018.01710

113. Ricciardi A, Visitsunthorn K, Dalton JP, Ndao M. A Vaccine Consisting of Schistosoma Mansoni Cathepsin B Formulated in Montanide ISA 720 VG Induces High Level Protection Against Murine Schistosomiasis. BMC Infect Dis (2016) 16(1):112. doi: 10.1186/s12879-016-1444-Z

114. Wei J, Versteeg L, Liu Z, Keegan B, Gazzinelli-Guimarães AC, Fujiwara RT, et al. Yeast-Expressed Recombinant As16 Protects Mice Against Ascaris Suum Infection Through Induction of a Th2-Skewed Immune Response. PloS Negl Trop Dis (2017) 11(7):e0005769. doi: 10.1371/journal.pntd.0005769

115. Golden O, Flynn RJ, Read C, Sekiya M, Donnelly SM, Stack C, et al. Protection of Cattle Against a Natural Infection of Fasciola Hepatica by Vaccination With Recombinant Cathepsin L1 (Rfhcl1). Vaccine (2010) 28 (34):5551-7. doi: 10.1016/j.vaccine.2010.06.039

116. Pérez-Caballero R, Siles-Lucas M, González-Miguel J, Martínez-Moreno FJ, Escamilla A, Pérez J, et al. Pathological, Immunological and Parasitological Study of Sheep Vaccinated With the Recombinant Protein 14-3-3z and Experimentally Infected With Fasciola Hepatica. Vet Immunol Immunopathol (2018) 202:115-21. doi: 10.1016/j.vetimm.2018.07.006

117. Rivera F, Espino AM. Adjuvant-Enhanced Antibody and Cellular Responses to Inclusion Bodies Expressing FhSAP2 Correlates With Protection of Mice to Fasciola Hepatica. Exp Parasitol (2016) 160:31-8. doi: 10.1016/j.exppara.2015.11.002

118. Zafra R, Buffoni L, Pérez-Caballero R, Molina-Hernández V, Ruiz-Campillo MT, Pérez J, et al. Efficacy of a Multivalent Vaccine Against Fasciola Hepatica Infection in Sheep. Vet Res (2021) 52(1):13. doi: 10.1186/s13567-021-00895-0

119. Wu HW, Fu ZQ, Lu K, Pond-tor S, Meng R, Hong Y, et al. Vaccination With Recombinant Paramyosin in Montanide ISA206 Protects Against Schistosoma Japonicum Infection in Water Buffalo. Vaccine (2017) 35 (26):3409-15. doi: 10.1016/j.vaccine.2017.05.007

120. Yang J, Zhu W, Huang J, Wang X, Sun X, Zhan B, et al. Partially Protective Immunity Induced by the 14-3-3 Protein From Trichinella Spiralis. Vet Parasitol (2016) 231:63-8. doi: 10.1016/j.vetpar.2016.06.028

121. Xu J, Bai X, Wang LB, Shi HN, van der Giessen JWB, Boireau P, et al. Influence of Adjuvant Formulation on Inducing Immune Response in Mice Immunized With a Recombinant Serpin From Trichinella Spiralis. Parasite Immunol (2017) 39(7):e12437. doi: 10.1111/pim.12437

122. Zhan B, Arumugam S, Kennedy MW, Tricoche N, Lian L-Y, Asojo OA, et al. Ligand Binding Properties of Two Brugia Malayi Fatty Acid and Retinol (FAR) Binding Proteins and Their Vaccine Efficacies Against Challenge Infection in Gerbils. PloS Negl Trop Dis (2018) 12(10):e0006772. doi: 10.1371/journal.pntd.0006772

123. Baccili CC, Martin CC, Decaris N, Madureira KM, Chase C, Gomes V. Effects of 3 Different Commercial Vaccines Formulations Against BVDV and BHV-1 on the Inflammatory Response of Holstein Heifers. Vet Sci (2019) 6 (3):69. doi: 10.3390/vetsci6030069
124. VanHoy G, Carman M, Habing G, Lakritz J, Hinds CA, Niehaus A, et al. Safety and Serologic Response to a Haemonchus Contortus Vaccine in Alpacas. Vet Parasitol (2018) 252:180-6. doi: 10.1016/j.vetpar.2018.02.014

125. Zafra R, Pérez-Écija RA, Buffoni L, Moreno P, Bautista MJ, Martínez-Moreno A, et al. Early and Late Peritoneal and Hepatic Changes in Goats Immunized With Recombinant Cathepsin L1 and Infected With Fasciola Hepatica. J Comp Pathol (2013) 148(4):373-84. doi: 10.1016/j.jcpa.2012.08.007

126. Mendes RE, Zafra R, Pérez-Écija RA, Buffoni L, Martínez-Moreno Á, Tendler M, et al. Evaluation of Local Immune Response to Fasciola Hepatica Experimental Infection in the Liver and Hepatic Lymph Nodes of Goats Immunized With Sm14 Vaccine Antigen. Mem Inst Oswaldo Cruz (2010) 105(5):698-705. doi: 10.1590/S0074-02762010000500017

127. Mendes RE, Pérez-Écija RA, Zafra R, Buffoni L, Martínez-Moreno Á, Dalton JP, et al. Evaluation of Hepatic Changes and Local and Systemic Immune Responses in Goats Immunized With Recombinant Peroxiredoxin (Prx) and Challenged With Fasciola Hepatica. Vaccine (2010) 128(16):2832-40. doi: 10.1016/j.vaccine.2010.01.055

128. Buffoni L, Martínez-Moreno FJ, Zafra R, Mendes RE, Pérez-Écija A, Sekiya $\mathrm{M}$, et al. Humoral Immune Response in Goats Immunised With Cathepsin L1, Peroxiredoxin and Sm14 Antigen and Experimentally Challenged With Fasciola Hepatica. Vet Parasitol (2012) 185(2-4):315-21. doi: 10.1016/ j.vetpar.2011.09.027

129. Villa-Mancera A, Olivares-Pérez J, Olmedo-Juárez A, Reynoso-Palomar A. Phage Display-Based Vaccine With Cathepsin L and Excretory-Secretory Products Mimotopes of Fasciola Hepatica Induces Protective Cellular and Humoral Immune Responses in Sheep. Vet Parasitol (2021) 289:109340. doi: 10.1016/j.vetpar.2020.109340

130. Villa-Mancera A, Reynoso-Palomar A, Utrera-Quintana F, Carreón-Luna L. Cathepsin L1 Mimotopes With Adjuvant Quil A Induces a Th1/Th2 Immune Response and Confers Significant Protection Against Fasciola Hepatica Infection in Goats. Parasitol Res (2014) 113(1):243-50. doi: 10.1007/s00436013-3650-6

131. Shi S, Zhu H, Xia X, Liang Z, Ma X, Sun B. Vaccine Adjuvants: Understanding the Structure and Mechanism of Adjuvanticity. Vaccine (2019) 37:3167-78. doi: 10.1016/j.vaccine.2019.04.055

132. Versteeg L, Wei J, Liu Z, Keegan B, Fujiwara RT, Jones KM, et al. Protective Immunity Elicited by the Nematode-Conserved As37 Recombinant Protein Against Ascaris Suum Infection. PloS Negl Trop Dis (2020) 14(2):e0008057. doi: 10.1371/journal.pntd.0008057

133. Perera DJ, Hassan AS, Jia Y, Ricciardi A, McCluskie MJ, Weeratna RD, et al. Adjuvanted Schistosoma Mansoni-Cathepsin B With Sulfated Lactosyl Archaeol Archaeosomes or AddaVax ${ }^{\mathrm{TM}}$ Provides Protection in a PreClinical Schistosomiasis Model. Front Immunol (2020) 11:605288. doi: 10.3389/fimmu.2020.605288/full

134. Hess JA, Zhan B, Torigian AR, Patton JB, Petrovsky N, Zhan T, et al. The Immunomodulatory Role of Adjuvants in Vaccines Formulated With the Recombinant Antigens Ov-103 and Ov-RAL-2 Against Onchocerca Volvulus in Mice. McSorley HJ. PloS Negl Trop Dis (2016) 10(7):e0004797. doi: 10.1371/journal.pntd.0004797

135. Martínez-Fernández AR, Nogal-Ruiz JJ, López-Abán J, Ramajo V, Oleaga A, Manga-González Y, et al. Vaccination of Mice and Sheep With Fh12 FABP From Fasciola Hepatica Using the New Adjuvant/Immunomodulator System ADAD. Vet Parasitol (2004) 126(3):287-98. doi: 10.1016/ j.vetpar.2004.07.023

136. Hernández-Goenaga J, López-Abán J, Protasio AV, Vicente Santiago B, del Olmo E, Vanegas M, et al. Peptides Derived of Kunitz-Type Serine Protease Inhibitor as Potential Vaccine Against Experimental Schistosomiasis. Front Immunol (2019) 10:2498. doi: 10.3389/fimmu.2019.02498/full

137. Vicente B, López-Abán J, Rojas-Caraballo J, Pérez del Villar L, Hillyer GV, Martínez-Fernández AR, et al. A Fasciola Hepatica-Derived Fatty Acid Binding Protein Induces Protection Against Schistosomiasis Caused by Schistosoma Bovis Using the Adjuvant Adaptation (ADAD) Vaccination System. Exp Parasitol (2014) 145(1):145-51. doi: 10.1016/j.exppara. 2014.08.007

138. Li L, Petrovsky N. Molecular Mechanisms for Enhanced DNA Vaccine Immunogenicity. Expert Rev Vaccines (2016) 15:313-29. doi: 10.1586/ 14760584.2016 .1124762 
139. Yang Lee LY, Izzard L, Hurt Ac. A Review of DNA Vaccines Against Influenza. Front Immunol Front Media SA (2018) 9:1568. doi: 10.3389/ fimmu.2018.01568

140. Porter KR, Raviprakash K. DNA Vaccine Delivery and Improved Immunogenicity. Curr Issues Mol Biol Curr Issues Mol Biol (2017) 22:12938. doi: 10.21775/cimb.022.129

141. Suschak JJ, Williams JA, Schmaljohn CS. Advancements in DNA Vaccine Vectors, Non-Mechanical Delivery Methods, and Molecular Adjuvants to Increase Immunogenicity. Hum Vaccines Immunotherapeut (2017) 13:283748. doi: 10.1080/21645515.2017.1330236

142. Li L, Petrovsky N. Molecular Adjuvants for DNA Vaccines. Curr Issues Mol Biol (2017) 22:17-40. doi: 10.21775/cimb.022.017

143. Liu HF, Li W, Lu MB, Yu LJ. Pharmacokinetics and Risk Evaluation of DNA Vaccine Against Schistosoma Japonicum. Parasitol Res (2013) 112(1):59-67. doi: 10.1007/s00436-012-3104-6

144. Kutzler MA, Weiner DB. DNA Vaccines: Ready for Prime Time? Nat Rev Genet (2008) 9:776-88. doi: 10.1038/nrg2432

145. Wesołowska A, Zawistowska-Deniziak A, Norbury LJ, Wilkowski P, Januszkiewicz K, Pyziel AM, et al. Immune Responses in Rats and Sheep Induced by a DNA Vaccine Containing the Phosphoglycerate Kinase Gene of Fasciola Hepatica and Liver Fluke Infection. Acta Parasitol (2016) 61 (2):212-20. doi: 10.1515/ap-2016-0030

146. Wiśniewski M, Jaros S, Baska P, Cappello M, Długosz E, Wedrychowicz H. Hamsters Vaccinated With Ace-Mep-7 DNA Vaccine Produced Protective Immunity Against Ancylostoma Ceylanicum Infection. Exp Parasitol (2016) 163:1-7. doi: 10.1016/j.exppara.2016.01.006

147. Gonçalves De Assis NR, Batistoni De Morais S, Figueiredo BCP, Ricci ND, De Almeida LA, Da Silva Pinheiro C, et al. DNA Vaccine Encoding the Chimeric Form of Schistosoma Mansoni Sm-TSP2 and Sm29 Confers Partial Protection Against Challenge Infection. PloS One (2015) 10(5):e0125075. doi: 10.1371/journal.pone.0125075

148. Lei N, Liu FC, Ren CP, Shen JJ, Liu M. An Efficient Schistosoma Japonicum Bivalent Membrane Protein Antigen DNA Vaccine Against Schistosomiasis in Mice. Med Sci Monit (2019) 25:9319-26. doi: 10.12659/MSM.919195

149. Wang X, Dai Y, Zhao S, Tang J, Li H, Xing Y, et al. PAMAM-Lys, a Novel Vaccine Delivery Vector, Enhances the Protective Effects of the SjC23 DNA Vaccine Against Schistosoma Japonicum Infection. PloS One (2014) 9(1): e86578. doi: 10.1371/journal.pone.0086578

150. Zhang W, Ahmad G, Torben W, Noor Z, Le L, Damian RT, et al. Sm-P80Based DNA Vaccine Provides Baboons With Levels of Protection Against Schistosoma Mansoni Infection Comparable to Those Achieved by the Irradiated Cercarial Vaccine. J Infect Dis (2010) 201(7):1105-12. doi: 10.1086/651147

151. Tang F, Xu L, Yan R, Song X, Li X. A DNA Vaccine Co-Expressing Trichinella Spiralis MIF and MCD-1 With Murine Ubiquitin Induces Partial Protective Immunity in Mice. J Helminthol (2013) 87(1):24-33. doi: 10.1017/S0022149X1100068X

152. Yang Y, Yang X, Gu Y, Wang Y, Zhao X, Zhu X. Protective Immune Response Induced by Co-Immunization With the Trichinella Spiralis Recombinant Ts87 Protein and a Ts87 DNA Vaccine. Vet Parasitol (2013) 194(2-4):207-10. doi: 10.1016/j.vetpar.2013.01.057

153. Wang J, Jiang Y, Yang W, Shi C, Huang H, Sun H, et al. Vaccination With DNA Encoding ES 43-kDa/45-kDa Antigens Significantly Reduces Trichinella Spiralis Infection in Mice. Res Vet Sci (2018) 120:4-10. doi: 10.1016/j.rvsc.2018.08.002

154. Gupta J, Misra S, Misra-Bhattacharya S. Immunization With Brugia Malayi Myosin as Heterologous DNA Prime Protein Boost Induces Protective Immunity Against B. Malayi Infection in Mastomys Coucha. PloS One (2016) 11(11):e0164991. doi: 10.1371/journal.pone.0164991

155. Joardar N, Mondal C, Sinha Babu SP. A Review on the Interactions Between Dendritic Cells, Filarial Parasite and Parasite-Derived Molecules in Regulating the Host Immune Responses. Scand J Immunol (2021) 93: e13001. doi: 10.1111/sji.13001

156. Sharma A, Sharma P, Vishwakarma AL, Srivastava M. Functional Impairment of Murine Dendritic Cell Subsets Following Infection With Infective Larval Stage 3 of Brugia Malayi. Infect Immun (2017) 85(1): e00818-16. doi: 10.1128/IAI.00818-16
157. Zhang W, Le L, Ahmad G, Molehin AJ, Siddiqui AJ, Torben W, et al. Fifteen Years of Sm-P80-Based Vaccine Trials in Nonhuman Primates: Antibodies From Vaccinated Baboons Confer Protection In Vivo and In Vitro From Schistosoma Mansoni and Identification of Putative Correlative Markers of Protection. Front Immunol (2020) 11:1246. doi: 10.3389/fimmu.2020.01246

158. Torben W, Ahmad G, Zhang W, Nash S, Le L, Karmakar S, et al. Role of Antibody Dependent Cell Mediated Cytotoxicity (ADCC) in Sm-P80Mediated Protection Against Schistosoma Mansoni. Vaccine (2012) 30 (48):6753-8. doi: 10.1016/j.vaccine.2012.09.026

159. Versteeg L, Almutairi MM, Hotez PJ, Pollet J. Enlisting the mRNA Vaccine Platform to Combat Parasitic Infections. Vaccines (2019) 7:122. doi: 10.3390/ vaccines 7040122

160. Oliver SE, Gargano JW, Marin M, Wallace M, Curran KG, Chamberland M, et al. The Advisory Committee on Immunization Practices' Interim Recommendation for Use of Pfizer-BioNTech COVID-19 Vaccine United States, December 2020. Morb Mortal Wkly Rep (2020) 69(50):1922. doi: 10.15585/mmwr.mm6950e2

161. US Food and Drug Administration. Vaccines and Related Biological Products Advisory Committee December 17, 2020 Meeting Briefing Document. FDA (2020) . Available at: https://www.fda.gov/advisory-committees/advisorycommittee-calendar/vaccines-and-related-biological-products-advisorycommittee-december-17-2020-meeting-announcement (Accessed April 15, 2021).

162. Maruggi G, Zhang C, Li J, Ulmer JB, Yu D. mRNA as a Transformative Technology for Vaccine Development to Control Infectious Diseases. Mol Ther (2019) 27:757-72. doi: 10.1016/j.ymthe.2019.01.020

163. Jackson LA, Anderson EJ, Rouphael NG, Roberts PC, Makhene M, Coler RN, et al. An mRNA Vaccine Against SARS-CoV-2 - Preliminary Report. N Engl J Med (2020) 383(20):1920-31. doi: 10.1056/NEJMoa2022483

164. Polack FP, Thomas SJ, Kitchin N, Absalon J, Gurtman A, Lockhart S, et al. Safety and Efficacy of the BNT162b2 mRNA Covid-19 Vaccine. N Engl J Med (2020) 383(27):2603-15. doi: 10.1056/NEJMoa2034577

165. Cafri G, Gartner JJ, Zaks T, Hopson K, Levin N, Paria BC, et al. mRNA Vaccine-Induced Neoantigen-Specific T Cell Immunity in Patients With Gastrointestinal Cancer. J Clin Invest (2020) 130(11):5976-88. doi: 10.1172/ JCI134915

166. Maruyama J, Mateer EJ, Manning JT, Sattler R, Seregin AV, Bukreyeva N, et al. Adenoviral Vector-Based Vaccine Is Fully Protective Against Lethal Lassa Fever Challenge in Hartley Guinea Pigs. Vaccine (2019) 37(45):682431. doi: 10.1016/j.vaccine.2019.09.030

167. Norton TD, Zhen A, Tada T, Kim J, Kitchen S, Landau NR. Lentiviral VectorBased Dendritic Cell Vaccine Suppresses HIV Replication in Humanized Mice. Mol Ther (2019) 27(5):960-73. doi: 10.1016/j.ymthe.2019.03.008

168. Yusuf Y, Yoshii T, Iyori M, Mizukami H, Fukumoto S, Yamamoto DS, et al. A Viral-Vectored Multi-Stage Malaria Vaccine Regimen With Protective and Transmission-Blocking Efficacies. Front Immunol (2019) 10:2412. doi: 10.3389/fimmu.2019.02412

169. Rothel JS, Boyle DB, Both GW, Pye AD, Waterkeyn JG, Wood PR, et al. Sequential Nucleic Acid and Recombinant Adenovirus Vaccination Induces Host-Protective Immune Responses Against Taenia Ovis Infection in Sheep. Parasite Immunol (1997) 19(5):221-7. doi: 10.1046/j.1365-3024.1997.d01-200.x

170. Smaill F, Jeyanathan M, Smieja M, Medina MF, Thanthrige-Don N, Zganiacz A, et al. A Human Type 5 Adenovirus-Based Tuberculosis Vaccine Induces Robust T Cell Responses in Humans Despite Preexisting Anti-Adenovirus Immunity. Sci Transl Med (2013) 5(205):205ra134. doi: 10.1126/ scitranslmed.3006843

171. Liu F, Fan X, Li L, Ren W, Han X, Wu X, et al. Development of Recombinant Goatpox Virus Expressing Echinococcus Granulosus EG95 Vaccine Antigen. J Virol Methods (2018) 261:28-33. doi: 10.1016/j.jviromet.2018.08.002

172. Liu F, Li L, Liu Y, Sun C, Liu C, Wu X, et al. Development of Reverse Genetics System for Small Ruminant Morbillivirus: Rescuing Recombinant Virus to Express Echinococcus Granulosus EG95 Antigen. Virus Res (2019) 261:50-5. doi: 10.1016/j.virusres.2018.12.008

173. Marsland BJ, Tisdall DJ, Heath DD, Mercer AA. Construction of a Recombinant Orf Virus That Expresses an Echinococcus Granulosus Vaccine Antigen From a Novel Genomic Insertion Site. Arch Virol (2003) 148(3):555-62. doi: 10.1007/s00705-002-0948-6 
174. Tan JL, Ueda N, Heath D, Mercer AA, Fleming SB. Development of Orf Virus as a Bifunctional Recombinant Vaccine: Surface Display of Echinococcus Granulosus Antigen EG95 by Fusion to Membrane Structural Proteins. Vaccine (2012) 30(2):398-406. doi: 10.1016/ j.vaccine.2011.10.079

175. Dutton S, Fleming SB, Ueda N, Heath DD, Hibma MH, Mercer AA. Delivery of Echinococcus Granulosus Antigen EG95 to Mice and Sheep Using Recombinant Vaccinia Virus. Parasite Immunol (2012) 34(6):312-7. doi: 10.1111/j.1365-3024.2012.01360.x

176. Hota-Mitchell S, Clarke MW, Podesta RB, Dekaban GA. Recombinant Vaccinia Viruses and Gene Gun Vectors Expressing the Large Subunit of Schistosoma Mansoni Calpain Used in a Murine Immunization- Challenge Model. Vaccine (1999) 17(11-12):1338-54. doi: 10.1016/S0264-410X(98) 00391-0

177. Wei F, Zhai Y, Jin H, Shang L, Men J, Lin J, et al. Development and Immunogenicity of a Recombinant Pseudorabies Virus Expressing Sj26GST and SjFABP From Schistosoma Japonicum. Vaccine (2010) 28(32):5161-6. doi: 10.1016/j.vaccine.2010.06.012

178. Dong B, Zarlenga DS, Ren X. An Overview of Live Attenuated Recombinant Pseudorabies Viruses for Use as Novel Vaccines. J Immunol Res (2014) 2014:824630. doi: 10.1155/2014/824630

179. Kelly BJ, Fraefel C, Cunningham AL, Diefenbach RJ. Functional Roles of the Tegument Proteins of Herpes Simplex Virus Type 1. Virus Res (2009) 145:173-86. doi: 10.1016/j.virusres.2009.07.007

180. Dai Y, Wang X, Zhao S, Tang J, Zhang L, Dai J, et al. Construction and Evaluation of Replication-Defective Recombinant Optimized Triosephosphate Isomerase Adenoviral Vaccination in Schistosoma Japonicum Challenged Mice. Vaccine (2014) 32(7):771-8. doi: 10.1016/ j.vaccine.2013.12.059

181. Dai Y, Wang X, Tang J, Zhao S, Xing Y, Dai J, et al. Enhancement of Protective Efficacy Through Adenoviral Vectored Vaccine Priming and Protein Boosting Strategy Encoding Triosephosphate Isomerase (SjTPI) Against Schistosoma Japonicum in Mice. PloS One (2015) 10(3):e0120792. doi: 10.1371/journal.pone.0120792

182. Logunov DY, Dolzhikova IV, Zubkova OV, Tukhvatullin AI, Shcheblyakov DV, Dzharullaeva AS, et al. Safety and Immunogenicity of an Rad26 and Rad5 Vector-Based Heterologous Prime-Boost COVID-19 Vaccine in Two Formulations: Two Open, Non-Randomised Phase 1/2 Studies From Russia. Lancet (2020) 396(10255):887-97. doi: 10.1016/S0140-6736(20)31866-3

183. Folegatti PM, Ewer KJ, Aley PK, Angus B, Becker S, Belij-Rammerstorfer S, et al. Safety and Immunogenicity of the ChAdOx1 Ncov-19 Vaccine Against SARS-CoV-2: A Preliminary Report of a Phase 1/2, Single-Blind, Randomised Controlled Trial. Lancet (2020) 396(10249):467-78. doi: 10.1016/S0140-6736(20)31604-4

184. Milligan ID, Gibani MM, Sewell R, Clutterbuck EA, Campbell D, Plested E, et al. Safety and Immunogenicity of Novel Adenovirus Type 26-and Modified Vaccinia Ankara-Vectored Ebola Vaccines: A Randomized Clinical Trial. JAMA - J Am Med Assoc (2016) 315(15):1610-23. doi: 10.1001/jama.2016.4218

185. Humphreys IR, Sebastian S. Novel Viral Vectors in Infectious Diseases. Immunology (2018) 153:1-9. doi: 10.1111/imm.12829

186. Sun W, Leist SR, McCroskery S, Liu Y, Slamanig S, Oliva J, et al. Newcastle Disease Virus (NDV) Expressing the Spike Protein of SARS-CoV-2 as a Live Virus Vaccine Candidate. EBioMedicine (2020) 62:103132. doi: 10.1016/ j.ebiom.2020.103132

187. Diemert DJ, Freire J, Valente V, Fraga CG, Talles F, Grahek S, et al. Safety and Immunogenicity of the Na-GST-1 Hookworm Vaccine in Brazilian and American Adults. PloS Negl Trop Dis (2017) 11(5):e0005574. doi: 10.1371/ journal.pntd.0005574

188. ClinicalTrials.gov. Safety and Immunogenicity Study of Na-GST-1 With or Without CpG. (2017). Available at: https://clinicaltrials.gov/ct2/show/ NCT02143518?term=helminth+vaccine\&draw=3\&rank=13 (Accessed April 2, 2021).

189. ClinicalTrials.gov. Safety and Immunogenicity of a Human Hookworm Candidate Vaccine With or Without Additional Adjuvant in Brazilian Adults. (2017). Available at: https://clinicaltrials.gov/ct2/show/ NCT01261130?term=helminth+vaccine\&draw=2\&rank=9 (Accessed April 2, 2021).
190. ClinicalTrials.gov. Safety and Immunogenicity of a Human Hookworm Candidate Vaccine With Different Doses of a Novel Adjuvant. (2017). Available at: https://clinicaltrials.gov/ct2/show/NCT01385189?term= helminth+vaccine\&draw=3\&rank=11 (Accessed April 2, 2021).

191. ClinicalTrials.gov. Safety and Immunogenicity of the Na-APR-1 Hookworm Vaccine in Healthy Adults. (2019). Available at: https://clinicaltrials.gov/ct2/ show/NCT01717950?term=helminth+vaccine\&draw=2\&rank=10 (Accessed April 2, 2021).

192. ClinicalTrials.gov. Safety and Immunogenicity of Co-Administered Hookworm Vaccine Candidates Na-GST-1 and Na-APR-1 in Gabonese Adults. ClinicalTrials.gov (2021). Available at: https://clinicaltrials.gov/ct2/ show/NCT02126462?term $=$ helminth+vaccine\&draw $=2 \&$ rank $=8$ (Accessed April 2, 2021)

193. Adegnika AA, de Vries SG, Zinsou FJ, Honkepehedji YJ, Dejon Agobé JC, Vodonou KG, et al. Safety and Immunogenicity of Co-Administered Hookworm Vaccine Candidates Na-GST-1 and Na-APR-1 in Gabonese Adults: A Randomised, Controlled, Double-Blind, Phase 1 Dose-Escalation Trial. Lancet Infect Dis (2021) 21(2):275-85. doi: 10.1016/S1473-3099(20) 30288-7

194. ClinicalTrials.gov. Immunisation, Treatment and Controlled Human Hookworm Infection (ITCHHI). (2019). Available at: https://clinicaltrials. gov/ct2/show/NCT03702530?term=vaccine\&cond=hookworm (Accessed April 2, 2021).

195. Diemert DJ, Pinto AG, Freire J, Jariwala A, Santiago H, Hamilton RG, et al. Generalized Urticaria Induced by the Na-ASP-2 Hookworm Vaccine: Implications for the Development Of Vaccines Against Helminths. $J$ Allergy Clin Immunol (2012) 130(1):169-76.E6. doi: 10.1016/ j.jaci.2012.04.027

196. Bethony JM, Simon G, Diemert DJ, Parenti D, Desrosiers A, Schuck S, et al. Randomized, Placebo-Controlled, Double-Blind Trial of the Na-ASP-2 Hookworm Vaccine in Unexposed Adults. Vaccine (2008) 26(19):2408-17. doi: 10.1016/j.vaccine.2008.02.049

197. ClinicalTrials.gov. Study of Na-ASP-2 Human Hookworm Vaccine in Healthy Adults Without Evidence of Hookworm Infection. (2017). Available at: https://clinicaltrials.gov/ct2/show/NCT00120081?term=vaccine\&cond= hookworm\&draw=2\&rank=3 (Accessed April 2, 2021).

198. ClinicalTrials.gov. Phase 1 Trial of Na-ASP-2 Hookworm Vaccine in Previously Infected Brazilian Adults. (2012). Available at: https:// clinicaltrials.gov/ct $2 /$ show/NCT00473967? term $=$ vaccine $\&$ cond $=$ hookworm\&draw=2\&rank=1 (Accessed April 2, 2021).

199. Riveau G, Schacht AM, Dompnier JP, Deplanque D, Seck M, Waucquier N, et al. Safety and Efficacy of the Rsh28gst Urinary Schistosomiasis Vaccine: A Phase 3 Randomized, Controlled Trial in Senegalese Children. PloS Negl Trop Dis (2018) 12(12):e0006968. doi: 10.1371/journal.pntd.0006968

200. ClinicalTrials.gov. Efficacy of Bilhvax in Association With Praziquantel for Prevention of Clinical Recurrences of Schistosoma Haematobium. (2012). Available at: https://clinicaltrials.gov/ct2/show/NCT00870649?term= vaccine $\&$ cond $=$ schistosomiasis $\&$ draw $=2 \&$ rank $=5$ (Accessed April 2, 2021).

201. Riveau G, Deplanque D, Remoué F, Schacht AM, Vodougnon H, Capron M, et al. Safety and Immunogenicity of Rsh28gst Antigen in Humans: Phase 1 Randomized Clinical Study of a Vaccine Candidate Against Urinary Schistosomiasis. PloS Negl Trop Dis (2012) 6(7):e1704. doi: 10.1371/ journal.pntd.0001704

202. ClinicalTrials.gov. Clinical Trial of Bilhvax,a Vaccine Candidate Against Schistosomiasis. (2013). Available at: https://clinicaltrials.gov/ct2/show/ NCT01512277? term $=$ vaccine $\&$ cond $=$ schistosomiasis $\&$ draw $=2 \&$ rank $=6$ (Accessed April 2, 2021)

203. Tendler M, Almeida MS, Vilar MM, Pinto PM, Limaverde-Sousa G. Current Status of the SM14/GLA-SE Schistosomiasis Vaccine: Overcoming Barriers and Paradigms Towards the First Anti-Parasitic Human(itarian) Vaccine. Trop Med Infect Dis (2018) 3:121. doi: 10.20944/preprints201810.0334.v1

204. ClinicalTrials.gov. Study of Safety and Immune Response of the Sm14 Vaccine in Adults of Endemic Regions. (2013). Available at: https://clinicaltrials.gov/ ct2/show/NCT03041766? term =vaccine \&cond=schistosomiasis \&draw $=$ 2\&rank=4 (Accessed April 2, 2021).

205. ClinicalTrials.gov. Anti-Schistosomiasis Vaccine: Sm14 Phase 2b-Sn in School Children. (2019). Available at: https://clinicaltrials.gov/ct2/show/ 
NCT03799510 term $=$ vaccine $\&$ cond $=$ schistosomiasis\&draw $=2 \& \mathrm{rank}=3$ (Accessed April 2, 2021).

206. Santini-Oliveira M, Coler RN, Parra J, Veloso V, Jayashankar L, Pinto PM, et al. Schistosomiasis Vaccine Candidate Sm14/GLA-SE: Phase 1 Safety and Immunogenicity Clinical Trial in Healthy, Male Adults. Vaccine (2016) 34 (4):586-94. doi: 10.1016/j.vaccine.2015.10.027

207. ClinicalTrials.gov. Study to Evaluate the Safety of the Vaccine Prepared Sm14 Against Schistosomiasis. ClinicalTrials.gov (2021). (2016). Available at: https://clinicaltrials.gov/ct2/show/NCT01154049?term=vaccine\&cond= schistosomiasis\&draw=2\&rank=1 (Accessed April 2, 2021).

208. ClinicalTrials.gov. Sm-TSP-2 Schistosomiasis Vaccine in Healthy Ugandan Adults. (2021). Available at: https://clinicaltrials.gov/ct2/show/ NCT03910972? term $=$ vaccine\& cond $=$ schistosomiasis\&draw $=2 \&$ rank $=2$ (Accessed April 2, 2021).

209. ClinicalTrials.gov. A Phase Ib Study of the Safety, Reactogenicity, and Immunogenicity of Sm-TSP-2/Alhydrogel)(R) With or Without AP 10-701 for Intestinal Schistosomiasis in Healthy Exposed Adults. (2021). Available at: https://clinicaltrials.gov/ct2/show/NCT03110757?term=vaccine\&cond= schistosomiasis\&draw=2\&rank=7 (Accessed April 2, 2021).

210. Keitel WA, Potter GE, Diemert D, Bethony J, El Sahly HM, Kennedy JK, et al. A Phase 1 Study of the Safety, Reactogenicity, and Immunogenicity of a Schistosoma Mansoni Vaccine With or Without Glucopyranosyl Lipid A Aqueous Formulation (GLA-AF) in Healthy Adults From a NonEndemic Area. Vaccine (2019) 37(43):6500-9. doi: 10.1016/j.vaccine. 2019.08.075

211. ClinicalTrials.gov. A Phase I Study of the Safety, Reactogenicity, and Immunogenicity of Sm-TSP-2/Alhydrogel ${ }^{\circledR}$ With or Without GLA-AF for Intestinal Schistosomiasis in Healthy Adults. (2017). Available at: https:// clinicaltrials.gov/ct $2 /$ show $/ \mathrm{NCT} 02337855$ ? term $=$ vaccine $\&$ cond $=$ schistosomiasis\&draw=2\&rank=9. (Accessed April 2, 2021).

212. Hagan P, Blumenthal UJ, Dunn D, Simpson AJ, Wilkins HA. Human IgE, IgG4 and Resistance to Reinfection With Schistosoma haematobium. Nature (1991) 349(6306):243-5. doi: 10.1038/349243a0

213. Laurens MB. RTS,S/AS01 Vaccine (Mosquiri ${ }^{\mathrm{TM}}{ }^{\mathrm{M}}$ ): An Overview. Hum Vaccines Immunother (2019) 16(3):480-9. doi: 10.1080/21645515.2019.1669415

214. World Health Organization. Malaria: The Malaria Vaccine Implementation Programme (MVIP). (2020). Available at: https://www.who.int/news-room/ q-a-detail/malaria-vaccine-implementation-programme (Accessed April 2, 2021).

215. Bruschi F, Korenaga M, Watanabe N. Eosinophils and Trichinella Infection: Toxic for the Parasite and the Host? Trends Parasitol (2008) 24(10):462-7. doi: 10.1016/j.pt.2008.07.001

216. Klion AD, Nutman TB. The Role of Eosinophils in Host Defense Against Helminth Parasites. J Allergy Clin Immunol (2004) 113(1):30-7. doi: 10.1016/ j.jaci.2003.10.050

217. Huang L, Appleton JA. Eosinophils in Helminth Infection: Defenders and Dupes. Trends Parasitol (2016) 32(10):798. doi: 10.1016/j.pt.2016.05.004

218. Gentil K, Hoerauf A, Layland LE. Eosinophil-Mediated Responses Toward Helminths. In: Lee JJ, Rosenberg HF, editors. Eosinophils in Health and Disease. New York: Elsevier (2013). pp. 303-12.

219. Ramalho-Pinto FJ, McLaren DJ, Smithers SR. Complement-Mediated Killing of Schistosomula of Schistosoma Mansoni by Rat Eosinophils In Vitro. J Exp Med (1978) 147(1):147-56. doi: 10.1084/jem.147.1.147

220. Sun GG, Lei JJ, Ren HN, Zhang Y, Guo KX, Long SR, et al. Intranasal Immunization With Recombinant Trichinella Spiralis Serine Protease Elicits Protective Immunity in BALB/c Mice. Exp Parasitol (2019) 201:1-10. doi: 10.1016/j.exppara.2019.04.006

221. Gupta J, Pathak M, Misra S, Misra-Bhattacharya S. CpG Enhances the Immunogenicity of Heterologous DNA-Prime/Protein-Boost Vaccination With the Heavy Chain Myosin of Brugia Malayi in BALB/c Mice. Parasitol Res (2019) 118(6):1943-52. doi: 10.1007/s00436-019-06318-6

222. Zhu L, Liu HF, Lu MB, Long QK, Shi YE, Yu LJ. Construction, Purification, and Evaluation of Multivalent DNA Vaccine Against Schistosoma Japonicum. Parasitol Res (2011) 108(1):115-21. doi: 10.1007/s00436-0102040-6

223. Dai Y, Wang X, Tang J, Zhao S, Xing Y, Dai J, et al. Enhancement of Protective Efficacy Through Adenoviral Vectored Vaccine Priming and Protein Boosting Strategy Encoding Triosephosphate Isomerase (SjTPI)
Against Schistosoma Japonicum in Mice. Rodrigues MM. PloS One (2015) 10(3):e0120792. doi: 10.1371/journal.pone.0120792

224. Ondigo BN, Ndombi EM, Nicholson SC, Oguso JK, Carter JM, Kittur N, et al. Functional Studies of $\mathrm{T}$ Regulatory Lymphocytes in Human Schistosomiasis in Western Kenya. Am J Trop Med Hyg (2018) 98(6):1770. doi: 10.4269/aitmh.17-0966

225. Zhou S, Qi Q, Wang X, Zhang L, Xu L, Dong L, et al. SjHSP60 Induces CD4+ CD25+Foxp3+ Tregs via TLR4-Mal-Drived Production of TGF- $\beta$ in Macrophages. Immunol Cell Biol (2018) 96(9):958-68. doi: 10.1111/ imcb. 12160

226. Zhou W, Yang Y, Mei C, Dong P, Mu S, Wu H, et al. Inhibition of RhoKinase Downregulates Th17 Cells and Ameliorates Hepatic Fibrosis by Schistosoma Japonicum Infection. Cells (2019) 8:1262. doi: 10.3390/ cells 8101262

227. Vuitton DA. Echinococcosis and Allergy. Clin Rev Allergy Immunol (2004) 26:93-104. doi: 10.1007/s12016-004-0004-2

228. Hoffmann KF, Cheever AW, Wynn TA. IL-10 and the Dangers of Immune Polarization: Excessive Type 1 and Type 2 Cytokine Responses Induce Distinct Forms of Lethal Immunopathology in Murine Schistosomiasis. J Immunol (2000) 164(12):6406-16. doi: 10.4049/jimmunol.164.12.6406

229. Babu S, Ganley LM, Klei TR, Shultz LD, Rajan TV. Role of Gamma Interferon and Interleukin-4 in Host Defense Against the Human Filarial Parasite Brugia Malayi. Infect Immun (2000) 68(5):3034-5. doi: 10.1128/ IAI.68.5.3034-3035.2000

230. Papayannopoulos V. Neutrophil Extracellular Traps in Immunity and Disease. Nat Rev Immunol (2017) 18(2):134-47. doi: 10.1038/nri.2017.105

231. Bouchery T, Moyat M, Sotillo J, Silverstein S, Volpe B, Coakley G, et al. Hookworms Evade Host Immunity by Secreting a Deoxyribonuclease to Degrade Neutrophil Extracellular Traps. Cell Host Microbe (2020) 27 (2):277-289.e6. doi: 10.1016/j.chom.2020.01.011

232. Bonne-Année S, Kerepesi LA, Hess JA, Wesolowski J, Paumet F, Lok JB, et al. Extracellular Traps Are Associated With Human and Mouse Neutrophil and Macrophage Mediated Killing of Larval Strongyloides Stercoralis. Microbes Infect (2014) 16(6):502-11. doi: 10.1016/j.micinf.2014.02.012

233. Paust S, von Andrian UH. Natural Killer Cell Memory. Nat Immunol (2011) 12(6):500-8. doi: 10.1038/ni.2032

234. Min-Oo G, Kamimura Y, Hendricks DW, Nabekura T, Lanier LL. Natural Killer Cells: Walking Three Paths Down Memory Lane. Trends Immunol (2013) 34(6):251-8. doi: 10.1016/j.it.2013.02.005

235. González-Hernández A, Coppernolle SV, Borloo J, Meulder FV, Paerewijck O, Peelaers I, et al. Host Protective ASP-Based Vaccine Against the Parasitic Nematode Ostertagia Ostertagi Triggers NK Cell Activation and Mixed IgG1-IgG2 Response. Sci Rep (2016) 6(1):1-12. doi: 10.1038/srep29496

236. MacDonald AJ, Cao L, He Y, Zhao Q, Jiang S, Lustigman S. rOv-ASP-1, a Recombinant Secreted Protein of the Helminth Onchocerca Volvulus, Is a Potent Adjuvant for Inducing Antibodies to Ovalbumin, HIV-1 Polypeptide and SARS-CoV Peptide Antigens. Vaccine (2005) 23(26):3446-52. doi: 10.1016/j.vaccine.2005.01.098

237. Van Meulder F, Van Coppernolle S, Borloo J, Rinaldi M, Li RW, Chiers K, et al. Granule Exocytosis of Granulysin and Granzyme B as a Potential Key Mechanism in Vaccine-Induced Immunity in Cattle Against the Nematode Ostertagia Ostertagi. Infect Immun (2013) 81(5):1798-809. doi: 10.1128/ IAI.01298-12

238. Cirovic B, de Bree LCJ, Groh L, Blok BA, Chan J, van der Velden WJFM, et al. BCG Vaccination in Humans Elicits Trained Immunity via the Hematopoietic Progenitor Compartment. Cell Host Microbe (2020) 28 (2):322-334.e5. doi: 10.1016/j.chom.2020.05.014

239. Yuan H, You-en S, Long-jiang Y, Xiao-hua Z, Liu-zhe L, Cash M, et al. Studies on the Protective Immunity of Schistosoma Japonicum Bivalent DNA Vaccine Encoding Sj23 and Sj14. Exp Parasitol (2007) 115(4):379-86. doi: 10.1016/j.exppara.2006.09.022

240. Donohue RE, Cross ZK, Michael E. The Extent, Nature, and Pathogenic Consequences of Helminth Polyparasitism in Humans: A Meta-Analysis. PloS Negl Trop Dis (2019) 13(6):e0007455. doi: 10.1371/journal.pnt d.0007455

241. Zimmermann P, Curtis N. Factors That Influence the Immune Response to Vaccination. Clin Microbiol Rev (2019) 32:e00084-18. doi: 10.1128/ CMR.00084-18 
242. Hu C, Zhu L, Luo R, Dao J, Zhao J, Shi Y, et al. Evaluation of Protective Immune Response in Mice by Vaccination the Recombinant Adenovirus for Expressing Schistosoma Japonicum Inhibitor Apoptosis Protein. Parasitol Res (2014) 113(11):4261-9. doi: 10.1007/s00436-014-4104-5

243. Minciullo PL, Cascio A, Isola S, Gangemi S. Different Clinical Allergological Features of Taenia Solium Infestation. Clin Mol Allergy (2016) 14(1):18. doi: 10.1186/s12948-016-0056-x

244. Milhau N, Almouazen E, Bouteille S, Hellel-Bourtal I, Azzouz-Maache S, Benavides $\mathrm{U}$, et al. In Vitro Evaluations on Canine Monocyte-Derived Dendritic Cells of a Nanoparticles Delivery System for Vaccine Antigen Against Echinococcus Granulosus. Haziot A. PloS One (2020) 15(2): e0229121. doi: 10.1371/journal.pone.0229121

245. Lee DH, Kim AR, Lee SH, Quan FS. Virus-Like Particles Vaccine Containing Clonorchis Sinensis Tegumental Protein Induces Partial Protection Against Clonorchis Sinensis Infection. Parasites Vectors (2017) 10(1):626. doi: 10.1186/s13071-017-2526-5

246. Fragoso G, Hernández M, Cervantes-Torres J, Ramírez-Aquino R, Chapula H, Villalobos N, et al. Transgenic Papaya: A Useful Platform for Oral Vaccines. Planta (2017) 245(5):1037-48. doi: 10.1007/s00425-017-2658-Z

247. Hassan AS, Zelt NH, Perera DJ, Ndao M, Ward BJ. Vaccination Against the Digestive Enzyme Cathepsin B Using a YS1646 Salmonella
Enterica Typhimurium Vector Provides Almost Complete Protection Against Schistosoma Mansoni Challenge in a Mouse Model. PloS Negl Trop Dis (2019) 13(12):e0007490. doi: 10.1371/journal. pntd.0007490

Conflict of Interest: The authors declare that the research was conducted in the absence of any commercial or financial relationships that could be construed as a potential conflict of interest.

Publisher's Note: All claims expressed in this article are solely those of the authors and do not necessarily represent those of their affiliated organizations, or those of the publisher, the editors and the reviewers. Any product that may be evaluated in this article, or claim that may be made by its manufacturer, is not guaranteed or endorsed by the publisher.

Copyright (C) 2021 Perera and Ndao. This is an open-access article distributed under the terms of the Creative Commons Attribution License (CC BY). The use, distribution or reproduction in other forums is permitted, provided the original author(s) and the copyright owner(s) are credited and that the original publication in this journal is cited, in accordance with accepted academic practice. No use, distribution or reproduction is permitted which does not comply with these terms. 